\title{
The hematopoietic factor G-CSF is a neuronal ligand that counteracts programmed cell death and drives neurogenesis
}

Armin Schneider, ${ }^{1}$ Carola Krüger, ${ }^{1}$ Tobias Steigleder, ${ }^{2,3,4}$ Daniela Weber, ${ }^{1}$ Claudia Pitzer, ${ }^{1}$ Rico Laage, ${ }^{1}$ Jaroslaw Aronowski, ${ }^{5}$ Martin H. Maurer, ${ }^{6}$ Nikolaus Gassler, ${ }^{7}$ Walter Mier, ${ }^{8}$ Martin Hasselblatt, ${ }^{9}$ Rainer Kollmar, ${ }^{3}$ Stefan Schwab, ${ }^{3}$ Clemens Sommer, ${ }^{10}$ Alfred Bach, ${ }^{1}$ Hans-Georg Kuhn, 4,11 and Wolf-Rüdiger Schäbitz ${ }^{2,3}$

\begin{abstract}
${ }^{1}$ Axaron Bioscience AG, Heidelberg, Germany. ${ }^{2}$ Department of Neurology, University of Münster, Münster, Germany. ${ }^{3}$ Department of Neurology, University of Heidelberg, Heidelberg, Germany. ${ }^{4}$ The Arvid Carlsson Institute for Neuroscience at the Institute for Clinical Neuroscience, Sahlgrenska Academy, Gothenburg University, Gothenburg, Sweden. ${ }^{5}$ Department of Neurology, University of Texas — Houston, Houston, Texas, USA. ${ }^{6}$ Institute for Physiology and Pathophysiology, ${ }^{7}$ Institute for Pathology, and ${ }^{8}$ Department of Nuclear Medicine, University of Heidelberg, Heidelberg, Germany. 9Institute for Neuropathology, University of Münster, Münster, Germany. ${ }^{10 D e p a r t m e n t ~ o f ~ N e u r o p a t h o l o g y, ~ J o h a n n e s ~ G u t e n b e r g-U n i v e r s i t y ~ o f ~ M a i n z, ~}$ Mainz, Germany. ${ }^{11}$ Department of Neurology, University of Regensburg, Regensburg, Germany.
\end{abstract}

\begin{abstract}
G-CSF is a potent hematopoietic factor that enhances survival and drives differentiation of myeloid lineage cells, resulting in the generation of neutrophilic granulocytes. Here, we show that G-CSF passes the intact bloodbrain barrier and reduces infarct volume in 2 different rat models of acute stroke. G-CSF displays strong antiapoptotic activity in mature neurons and activates multiple cell survival pathways. Both G-CSF and its receptor are widely expressed by neurons in the CNS, and their expression is induced by ischemia, which suggests an autocrine protective signaling mechanism. Surprisingly, the G-CSF receptor was also expressed by adult neural stem cells, and G-CSF induced neuronal differentiation in vitro. G-CSF markedly improved long-term behavioral outcome after cortical ischemia, while stimulating neural progenitor response in vivo, providing a link to functional recovery. Thus, G-CSF is an endogenous ligand in the CNS that has a dual activity beneficial both in counteracting acute neuronal degeneration and contributing to long-term plasticity after cerebral ischemia. We therefore propose G-CSF as a potential new drug for stroke and neurodegenerative diseases.
\end{abstract}

\section{Introduction}

Stroke remains one of the most urgent medical problems of our times, growing in importance due to the demographic changes in industrialized societies. Treatment with tissue-plasminogen activator is limited by side effects and by the fact that it must be initiated within a short window of time, so that only a small percentage of all stroke patients undergo thrombolysis (1). Numerous neuroprotective strategies aiming at important mechanisms such as glutamate toxicity or free radical formation have failed due to lack of efficacy or intolerable side effects. It is therefore believed that a successful treatment strategy should be well tolerated, not interfere with essential brain physiology, and approach several pathophysiological mechanisms in parallel. In addition to effects on acute infarct evolution, novel strategies should also impact long-term functional outcome. Recovery of specific functions and improvement of activities of daily living are caused by intrinsic changes in existing neurons or networks

Nonstandard abbreviations used: BBB, blood-brain barrier; bFGF, basic FGF; CCA, common carotid artery; DCX, doublecortin; DIV, days in vitro; GFAP, glial fibrillary acidic protein; MCA, middle cerebral artery; MCAO, MCA occlusion; NSE, neuron-specific enolase; NSS, neurological severity score; PARP, poly-ADP ribose polymerase; PLP, proteolipid protein; SVZ, subventricular zone; TTC, 2,3,5-triphenyl tetrazolium chloride.

Conflict of interest: A. Schneider, C. Krüeger, D. Weber, C. Pitzer, R. Laage, and A. Bach are employees of Axaron Bioscience AG. R. Kollmar, S. Schwab, C. Sommer, W.-R. Schäbitz, A. Schneider, C. Krüeger, D. Weber, M.H. Maurer, and N. Gassler are inventors on a patent application incorporating parts of the presented findings.

Citation for this article: J. Clin. Invest. 115:2083-2098 (2005).

doi:10.1172/JCI23559. or by the generation of new neurons from progenitor cells. Regarding the latter, enhancement of neurogenesis in the postischemic brain now appears to be an attractive strategy. Neural progenitor cells residing in the adult brain can indeed initiate a compensatory response to ischemic events that results in the production of new neurons $(2,3)$.

G-CSF is a $19.6-\mathrm{kDa}$ glycoprotein commonly used to treat neutropenia $(4,5)$. Known sources of G-CSF in the body include monocytes, mesothelial cells, fibroblasts, and endothelial cells, and receptors for G-CSF are present on precursors and mature neutrophilic granulocytes, monocytes, platelets, and endothelial cells. At the myeloid progenitor cell level, G-CSF stimulates the growth of neutrophil granulocyte precursors (6). G-CSF crucially regulates survival of mature, i.e., postmitotic, neutrophils (7) by inhibition of apoptosis (8).

We have recently uncovered the neuroprotective potential of G-CSF in an acute stroke model (9). Here, we explore the mechanisms responsible for that property and report on a dual functionality of G-CSF in the brain that parallels its activity in the hematopoietic system: inhibition of programmed cell death and stimulation of neuronal progenitor differentiation.

\section{Results}

G-CSF has robust neuroprotective activity in 2 different rodent stroke models and crosses the blood-brain barrier. We recently reported infarctreducing activity of G-CSF in the acute stroke model middle cerebral artery occlusion (MCAO) in rats when treatment was initiated 30 minutes after onset of ischemia (9). When we initiated treat- 


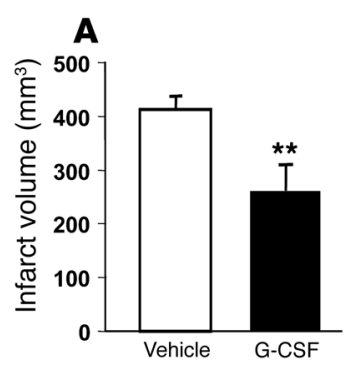

\section{B}
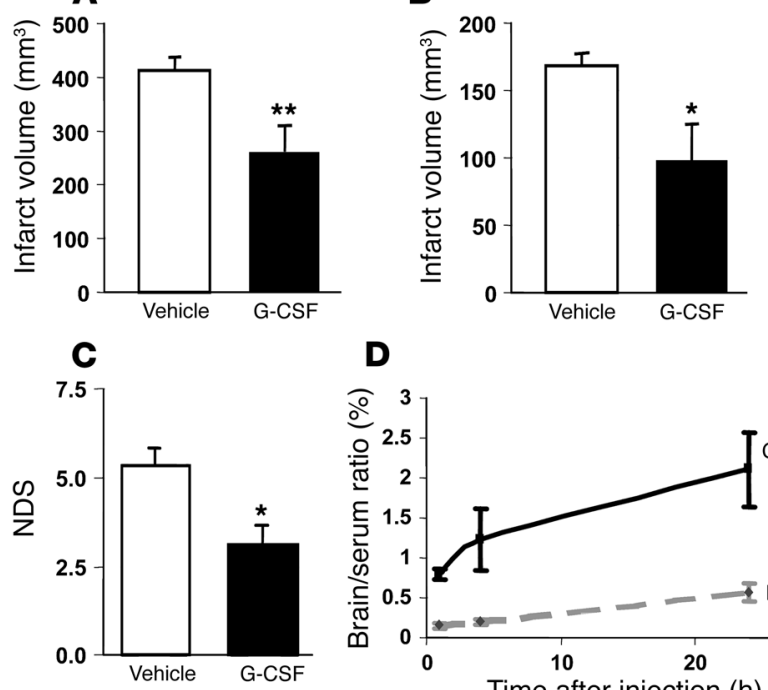

\section{D}

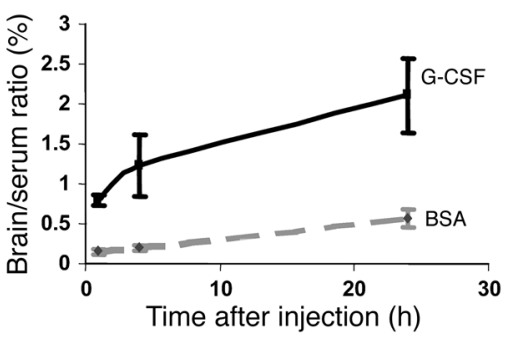

Figure 1

G-CSF has stable neuroprotective activity in focal cerebral ischemia and passes the intact BBB. (A) G-CSF has efficacy in the transient MCAO stroke model when given 2 hours after onset of ischemia, as shown by reduction in infarct volume (dose: $60 \mu \mathrm{g} / \mathrm{kg}$ i.v.; vehicle, $n=7$; G-CSF, $n=10 ;{ }^{* *} P<0.01$ by 2 -sided $t$ test). (B) G-CSF reduces infarct volume in the rat cortical combined CCA/distal MCA occlusion model when given 1 hour after onset of ischemia (dose: $50 \mu \mathrm{g} / \mathrm{kg}$ i.v.; $n=5$ each; ${ }^{*} P<0.05$ ). (C) Behavioral measurements in the cortical combined CCA/distal MCA occlusion model. G-CSF-treated animals have a better composite neurological deficit score (NDS) $\left({ }^{*} P<0.05\right)$. (D) Comparison of the brain/serum ratios of i.v. injected iodinated G-CSF and albumin at 1,4 , and 24 hours following injection. Albumin does not pass the BBB. Radiolabeled proteins (G-CSF and BSA) were injected via the tail vein of healthy female Sprague-Dawley rats. The relative amount of radiolabeled G-CSF and BSA in serum and brain was measured, and the ratio of brain/serum was plotted against the time. The brain/serum ratio of G-CSF was significantly greater than that of albumin, which indicated passage of the intact BBB in non-ischemic animals.

ment with G-CSF ( $60 \mu \mathrm{g} / \mathrm{kg}$ body weight i.v.) in a delayed fashion, 2 hours after onset of ischemia, we still observed that the infarct volume was robustly reduced, by $37 \%$ compared with that of vehicle-treated rats $(P<0.01$; Figure $1 \mathrm{~A})$. Mortality in the MCAO model was $27 \%$ in the control group (4 of 15 ) and $15 \%$ in the G-CSF-treated group (2 of 13). Moreover, in another model of cerebral ischemia, direct distal MCAO (10), G-CSF at a similar dose (50 $\mu \mathrm{g} / \mathrm{kg}$ body weight i.v.) given 1 hour after occlusion onset resulted in an infarct volume reduction of $42 \%(P<0.05$; Figure $1 \mathrm{~B})$. This infarct reduction correlated with behavioral improvements in the distal MCAO model (Figure 1C). In both models used, there was no difference in the physiological parameters obtained, such as blood pressure as well as blood glucose and blood gas levels, and the extent of drop in cerebral perfusion as monitored by laser Doppler flowmetry (data not shown). As expected, G-CSF treatment at a dose of $60 \mu \mathrm{g} / \mathrm{kg}$ body weight in rats subjected to MCAO led to about 2-fold elevations in leukocyte counts (neutrophils and monocytes) after 24 hours (Supplemental Figure 1; supplemental material available online with this article; doi:10.1172/ JCI23559DS1). In summary, G-CSF had a stable neuroprotective effect in 2 different infarct models.
A prerequisite for a direct action of G-CSF on the brain would be penetration of the blood-brain barrier (BBB). We determined the amount of iodinated G-CSF (131 I-G-CSF) in brain and serum at 1,4 , and 24 hours after i.v. injection in noninjured rats and calculated the brain/serum ratios of ${ }^{131} \mathrm{I}-\mathrm{G}-\mathrm{CSF}$ and ${ }^{131} \mathrm{I}$-albumin as an index of BBB permeability. At every observation point, G-CSF showed a higher brain/serum ratio, which indicated passage of G-CSF through the intact BBB (Figure 1D).

$G$-CSF receptor and ligand are neuronally expressed and induced by cerebral ischemia. The G-CSF receptor showed a broad, predominantly neuronal expression throughout the rat brain, with particularly high immunopositivity in large principal neurons. Among brain regions, there was a high expression in the cortex (most pronounced in layers II and V) (Figure 2A), the hippocampus, the subventricular zone (SVZ), the cerebellum (particularly in Purkinje cells) (Figure 2B) as well as deep cerebellar (Figure 2C) and brainstem nuclei plus the mitral cells in the olfactory bulb. Importantly, a corresponding neuronal staining pattern was also confirmed for human (Figure 2D: frontal cortex, layer V) and mouse (data not shown) brain tissue. Also, specificity of the G-CSF receptor signal was demonstrated in neural and extraneural tissues by preincubation with the target peptide (Supplemental Figure 2). In a search for sources for the ligand in the CNS, we found expression of G-CSF in all brain regions where its receptor was expressed. For example, we observed strong expression in the hippocampus CA3 field (Figure $2 \mathrm{E}$ ), the hilus and subgranular zone of the dentate gyrus (Figure $2 \mathrm{E}$, arrows), neurons in the entorhinal cortex (Figure $2 \mathrm{~F}$ ), neurons in the olfactory bulb (Figure 2G), several cerebellar and brainstem nuclei (Figure 2H), and cells in the SVZ (Figure 2I). Positive control stainings using the identical staining protocol and antibody employed in Figure 2, F-I, yielded the expected published staining patterns for G-CSF in extraneural tissues (Supplemental Figure 3). In addition, neuronal expression was also detected using a second, unrelated antibody against G-CSF (Supplemental Figure 4).

We then performed a series of experiments to confirm the true neuronal expression of this secreted protein. As 1 report mentioned described G-CSF expression in stimulated astrocytes in vitro (11), we performed double-immunohistochemistry with the astrocytic marker glial fibrillary acidic protein (GFAP). There was no appreciable astrocytic expression of G-CSF detectable in vivo in all brain regions examined, both in noninjured and ischemic brains. Figure 3 shows examples of the dentate gyrus hilus (Figure 3A) and cortex (Figure $3 \mathrm{~B}$ ). In contrast, costaining with the neuronal marker NeuN demonstrated perfect colocalization with G-CSF (Figure 3C). Moreover, the pattern of G-CSF mRNA detection in neurons of brain areas by in situ hybridization corresponded to the staining pattern obtained by immunohistochemistry, which confirmed neuronal synthesis of G-CSF (Figure 3, D-I). Note the distinct staining in selected cells in the subgranular zone of the dentate gyrus (Figure 3H). Finally, we performed laser-capture microdissection of neurons and astrocytes from the mouse frontal cortex and assayed these samples for G-CSF mRNA expression by PCR. Indeed, using this highly sensitive approach, we could readily detect G-CSF expression in the neuronal sample but not in astrocytes, even after 50 cycles of PCR amplification (Figure 3J). Thus, $\mathrm{G}-\mathrm{CSF}$ is a neuronally expressed protein in the CNS.

Astonishingly, G-CSF localized to neurons expressing its receptor in all areas examined (Figure 4), which suggests an autocrine activation mechanism of the receptor. We asked whether this ligand/receptor system reacts to cerebral ischemia. Indeed, after 


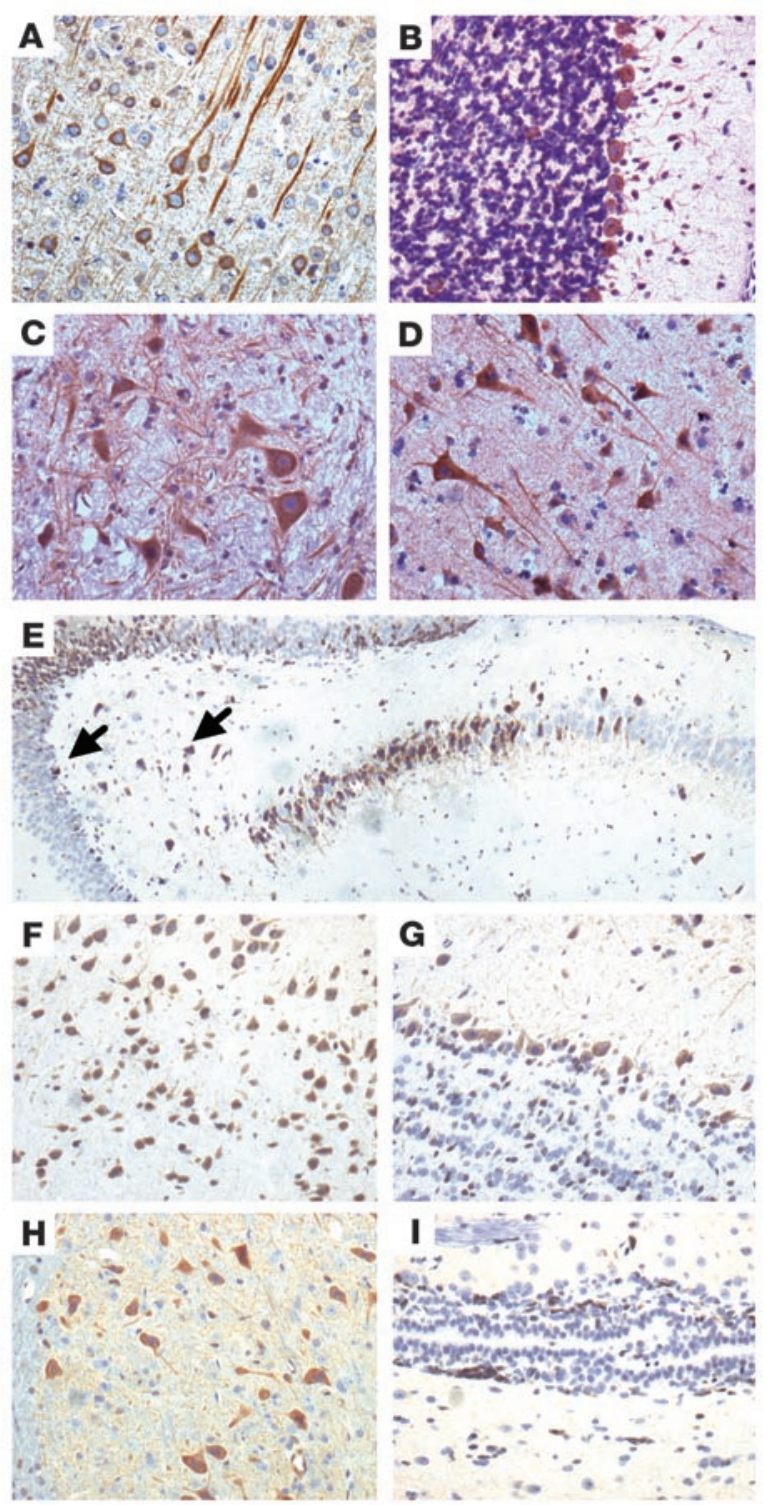

2 hours reperfusion in the MCAO stroke model, there was a dramatic upregulation of the ligand on the ipsilateral forebrain hemisphere (more than 100-fold according to quantitative PCR; Figure $5 \mathrm{~A})$ that was accompanied by induction of G-CSF mRNA on the contralateral hemisphere. At 6 hours following ischemia, this induction became more specific to the ischemic hemisphere, and it was no longer detectable at 20 hours of reperfusion. This upregulation of the ligand was accompanied by a more modest induction of the G-CSF receptor at 6 hours (Figure $5 \mathrm{~B}$ ), more prominent in the ipsilateral than the contralateral hemisphere. A more distinct induction of G-CSF receptor mRNA at 6 hours was seen in periinfarct cortex samples from a rat cortical photothrombotic model (Figure 5C). In addition, we could also detect ligand induction in a global model of cerebral ischemia (Supplemental Figure 5).

This mRNA upregulation by cerebral ischemia was confirmed on the protein level by immunohistochemistry at 6 hours following ischemia (Figure 5, D-O). Induction of receptor and ligand was most clearly seen in the periinfarct area, e.g., in the MCAO model (Figure 5, D [receptor] and G [ligand]), or in cortical photothrom-

\section{Figure 2}

The G-CSF receptor $(\mathbf{A}-\mathbf{D})$ and its ligand $(\mathbf{E}-\mathbf{I})$ are expressed by neurons in a variety of brain regions in the rat. Among other areas, expression of the receptor was detected in pyramidal cells in cortical layer V (A); Purkinje cells in the cerebellum (B); and cerebellar nuclei (C). Importantly, this neuronal staining pattern could also be detected in the human brain (frontal cortex, D). G-CSF is expressed by neurons in many areas of the CNS. Immunohistochemistry identifies G-CSF-positive cells in the CA3 region of the hippocampus (E) and the subgranular zone and hilus of the dentate gyrus (E, arrows), the entorhinal cortex $(\mathbf{F})$, the olfactory bulb $(\mathbf{G})$, and cerebellar nuclei $(\mathbf{H})$. Expression was also seen in cells in the SVZ (I).

botic ischemia, where the infarct borders are easily recognizable (Figure 5, J [receptor] and M [ligand]). In conclusion, G-CSF and its receptor are coexpressed in neurons in the rodent CNS and are upregulated by ischemic stimuli.

We then asked whether these data from the rodent are likely relevant to the human system. Indeed, when comparing the cortical periinfarct area from a human stroke case 3 days after stroke onset (Figure 6A) with the corresponding contralateral cortex (Figure $6 \mathrm{~B}$ ) or a neuropathologically normal matched control brain (Figure $6 \mathrm{C}$ ), we found clear induction of G-CSF receptor expression in neurons (see insets), which suggests comparable activity of the G-CSF system in the human brain.

G-CSF activates antiapoptotic pathways in cultured neurons. As G-CSF blocks apoptosis in cells of the myeloid lineage, we hypothesized that G-CSF might also interfere with programmed cell death in neurons. Cortical neurons from rat cortex at E18 invariably expressed the G-CSF receptor (Figure 7A). G-CSF protected cortical neurons against programmed cell death caused by the apoptosis inducer camptothecin (Figure 7B). This activity appeared to be mediated via the neuronal G-CSF receptor, as an antibody against the receptor was able to abolish protection (Figure 7C). Activity of G-CSF against neuronal cell death resulting from other apoptosis-inducing agents could also be observed. An apoptotic stimulus for neurons with high relevance to stroke pathophysiology is NO. G-CSF reduced NO-induced poly-ADP ribose polymerase (PARP) and caspase-3 cleavage in primary neurons (Figure 7D). This antiapoptotic activity was not specific to cells of rodent origin but could also be seen in NO-challenged human SHSY-5Y neuroblastoma cells (Figure 7E), which also expressed the G-CSF receptor (data not shown). We therefore analyzed the activation of antiapoptotic pathways after G-CSF stimulation in primary cortical neurons.

One important known transduction factor of G-CSF in the hematopoietic system is STAT3. Although activation of STAT3 by phosphorylation was detected in neurons after 5 minutes of G-CSF exposure (Figure 8, A and B), this induction was rather moderate and very transient. STAT3 is phosphorylated by the JAK2 kinase, which is recruited to the intracellular domains of the G-CSF receptor upon ligand binding. STAT3 activation appeared to be specifically mediated via the known pathway involving the G-CSF receptor present on neurons (Figure 8A, bottom lane), as AG490, a specific JAK2 inhibitor, strongly reduced STAT3 phosphorylation 5 minutes after addition of G-CSF (Figure 8A, right). Typical for the kinetics of G-CSF-activated STAT3 in the hematopoietic lineage (12), STAT phosphorylation decreased rapidly over a time course of 60 minutes (Figure $8 \mathrm{~B}$ ). G-CSF also led to a longlasting (at least 8 hours), but overall moderate increase in protein 

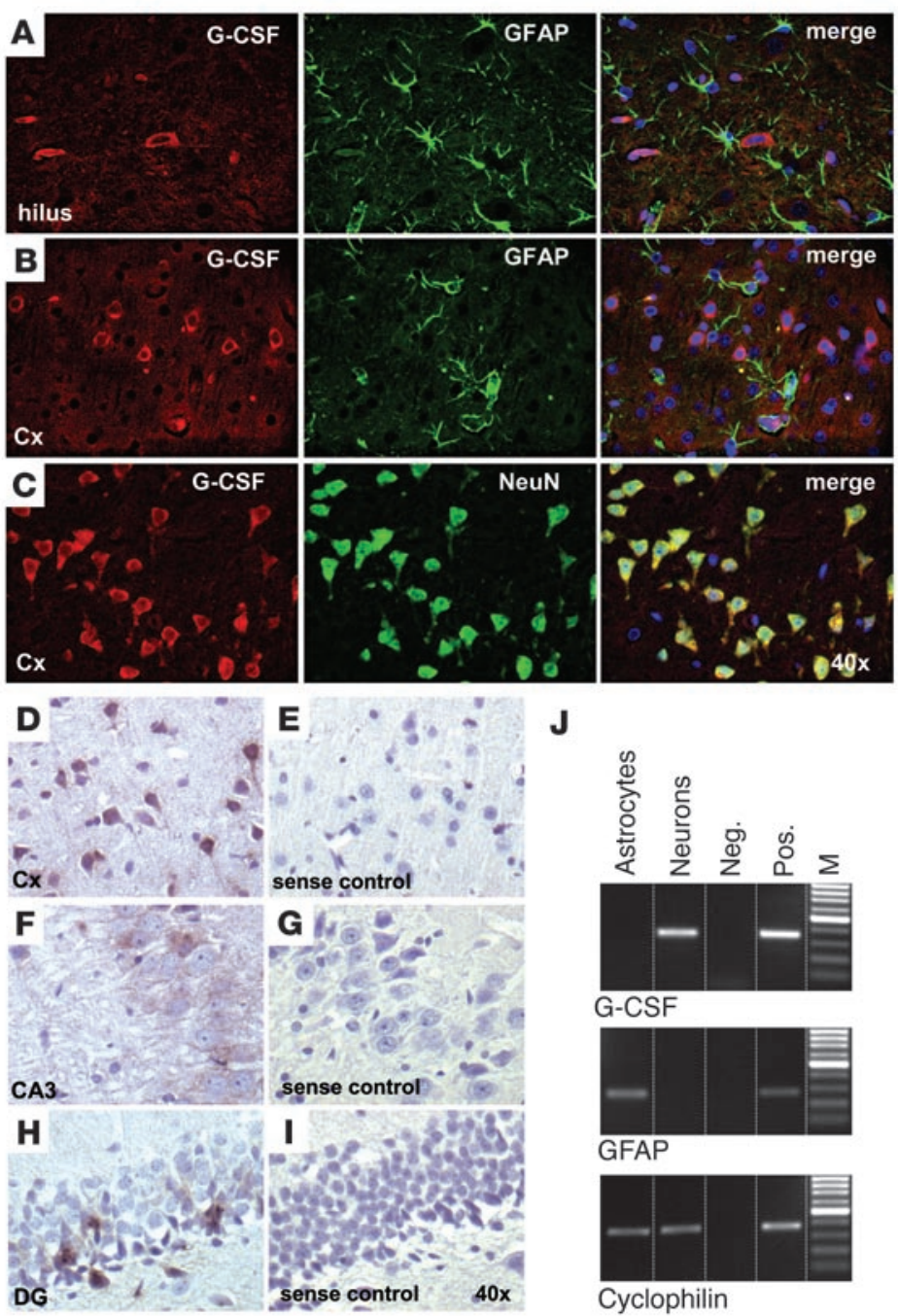

J

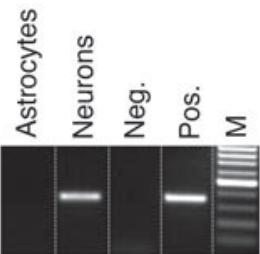

G-CSF

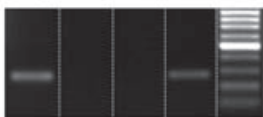

GFAP

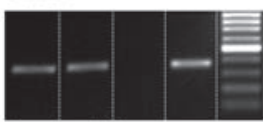

Cyclophilin

levels of the STAT3 target $\mathrm{Bcl}-\mathrm{X}_{\mathrm{L}}$, a potent antiapoptotic factor in neurons (13) (Figure 8C).

Next, we determined activation levels of the ERK family of kinases. ERK1/2, which has been linked to both pro- and antiapoptotic events in neurons (e.g., refs. 14, 15) was only weakly and transiently activated by G-CSF (Figure 8D). In contrast, the newly described ERK5 kinase demonstrated a strong and lasting activation pattern (Figure 8D, bottom 2 rows). Interestingly, a recent report connects ERK5 activation to survival signals elicited by trk receptors (16).

One of the most potent antiapoptotic transduction pathways in all cell types including neurons known to date is the PI3K/Akt pathway (17). Akt is activated via PI3K and $3^{\prime}$-phosphoinositide-dependent protein kinase (PDK), and the amount of active Akt can be determined based on Ser 437 phosphorylation. In

\section{Figure 3}

G-CSF is specifically expressed by neurons in the rat CNS. (A-C) Double-immunofluorescence staining with the astrocytic marker GFAP revealed absence of G-CSF expression in astrocytes in the hilus of the dentate gyrus (A) or cortex (Cx; B). In contrast, there was perfect colocalization of G-CSF with cells expressing the neuronal marker NeuN (C). (D-I) In situ hybridization confirmed the neuronal expression of G-CSF and demonstrated an expression pattern that paralleled results obtained by immunohistochemistry. For example, G-CSF mRNA was detected in pyramidal neurons in the cortex (D; original magnification, $\times 40$ ), in the hippocampus CA3 field (F; original magnification, $\times 40$ ), and in specific cells located in or near the subgranular zone in the dentate gyrus (DG) $(\mathbf{H}$; original magnification, $\times 40$ ). Sense probes did not yield any specific staining in corresponding sections $(E, G$, and $\mathbf{I}$; original magnification, $\times 40)$. (J) Using amplified mRNA from laser-excised neurons or astrocytes from the mouse cortex (100 cells each), a G-CSF-specific PCR signal could only be obtained in the neuronal pool but not from astrocytes after 50 amplification cycles. As a control, GFAP was amplified only from the astrocytic population, whereas the ubiquitous housekeeping gene cyclophilin was amplified from both cell pools. A brain cDNA library served as positive control (Pos.) for all PCR reactions. PCR reactions using water as input served as negative control (Neg.). M, size marker.

untreated neurons, there was only a faint band visible corresponding to phosphorylated Akt (Figure 8E, bottom 2 rows). However, 5 minutes after G-CSF exposure, levels of phosphorylated Akt dramatically increased, and they remained elevated for at least 1 hour. The kinetics of Akt activation following G-CSF exposure corresponded well with the phosphorylation of PDK1, the protein kinase immediately upstream of Akt in the PI3K/Akt pathway (Figure 8E, top 2 rows). The phosphorylation of Akt 5 minutes after addition of G-CSF was completely blocked by the PI3K inhibitor LY294002 (Figure 8E, right). Thus, Akt is a prominent signal induced by G-CSF in neurons and appears to be activated via the known PI3K/PDK pathway originating at the G-CSF receptor. Inhibition of PI3K by LY294002 was able to partially block G-CSF-mediated protection against apoptosis in neurons (Figure $8 \mathrm{~F}$ ) or in human neuroblastoma cells (Figure 8G), which suggests that Akt activation indeed is a crucial factor in G-CSF's antiapoptotic activity.

In conclusion, these results indicate that G-CSF counteracts programmed cell death in neuronal cells, an activity that is at least partially mediated by the PI3K/Akt pathway.

$G$-CSF drives neuronal differentiation in vitro. We noted that G-CSF receptor and ligand were expressed in the dentate gyrus by neurons of the subgranular zone and the hilus region (for examples, see Figure 2E, arrows and Figure 3, H and I). Expression was also noted in cells of the SVZ (Figure 2I). As these regions are known

\section{Figure 4}

The G-CSF receptor and its ligand colocalize in neurons in the cortex. Double-immunofluorescence detected G-CSF receptor (G-CSFR) (A) and G-CSF itself (B) in identical layer $\mathrm{V}$ neurons in the frontal cortex. Note the relatively stronger presence of the receptor in dendritic processes (C).
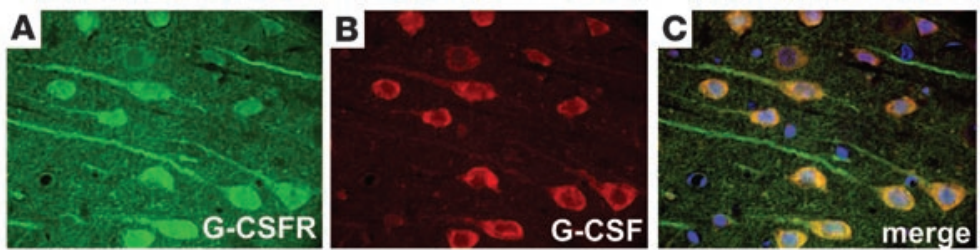
to harbor neuronal progenitor cells and G-CSF has a potent role in progenitor cell differentiation in the hematopoietic system, we asked whether G-CSF might have a functional role in differentiation of adult neural stem cells. Indeed, adult neural stem cells isolated from the rat $\mathrm{SVZ}$ or hippocampal region that grow as neurospheres in culture expressed the G-CSF receptor at the mRNA level (Figure 9A). By immunocytochemistry we could also detect colocalization with the stem cell marker nestin (Figure 9B). We therefore examined the effects of G-CSF treatment on adult neural stem cells. G-CSF dose-dependently induced activity of the promoter of the mature neuronal marker $\beta$-III-tubulin (Figure 9C) with a maximal induction greater than that reached by the most standard neuronal induction protocol (addition of FCS and withdrawal of EGF and basic FGF [bFGF]) (Figure 9C, far right bar). We corroborated this result by measuring expression levels of cell type-specific differentiation markers (nestin, $\beta$-III-tubulin, neuron-specific enolase [NSE], proteolipid protein [PLP], and GFAP) by quantitative PCR after 4 days of G-CSF treatment. G-CSF again led to a dosedependent increase in the expression of markers for neuronal differentiation ( $\beta$-III-tubulin and NSE) and a slight increase in the expression of mature glial markers (PLP, GFAP; Figure 9D). The expression of nestin stayed constant with increasing concentrations of G-CSF, which indicated that G-CSF treatment did not diminish the pool of undifferentiated cells (Figure 9D). As a third approach to assay neuronal differentiation, we used FACS analysis to determine the number of microtubule-associated protein 2-positive (MAP2-positive) cells after G-CSF treatment. Also in this assay, G-CSF led to an increase in the population of cells expressing mature neuronal markers (Figure 9E). Thus, the G-CSF system has a functional role in the regulation of differentiation of adult neural stem cells in vitro.

G-CSF improves functional outcome after cerebral ischemia. To determine whether these basic properties of G-CSF had consequences for long-term postischemic behavioral changes and for neurogenesis in vivo, we designed an experiment wherein

\section{Figure 5}

G-CSF and its receptor are induced by cerebral ischemia. (A-C) Quantitative PCR demonstrates induction of mRNA following cerebral ischemia. (A) In the MCAO model, G-CSF mRNA is induced more than 100-fold in the ipsilateral and contralateral forebrain hemisphere at 2 hours following ischemia. At 6 hours, induction levels dropped, and overexpression became more specific to the ipsilateral hemisphere. At 20 hours, induction was no longer detectable (data not shown). (B) Moderate induction of the G-CSF receptor mRNA in forebrain hemispheres was seen 6 hours following MCAO. (C) Receptor induction was also detected 6 hours after ischemia in another ischemic model, cortical photothrombotic ischemia in biopsy material from the periinfarct cortex. The substantially higher induction reflects the strong induction in the infarct penumbral zone. (D-0) Immunohistochemical detection of receptor and ligand in the corresponding ischemia models. (D-I) Staining for G-CSF receptor (D-F) and ligand (G-I) in the MCAO model, 6 hours after ischemia: ipsilateral cortex ( $\mathbf{D}$ and $\mathbf{G}$ ) and corresponding areas of the contralateral hemisphere ( $\mathbf{E}$ and $\mathbf{H})$ and the cortex of a sham-operated rat ( $\mathbf{F}$ and $\mathbf{I})$. (J-O) Staining for G-CSF receptor (J-L) and G-CSF itself $(\mathbf{M}-\mathbf{O})$ in the photothrombotic model: ipsilateral cortex ( $\mathbf{J}$ and $\mathbf{M}$ ) and corresponding areas of the contralateral hemisphere ( $\mathbf{K}$ and $\mathbf{N}$ ) and the cortex of a sham-operated rat ( $\mathbf{L}$ and $\mathbf{O})$. The infarct border zone is shown in the upper-right quadrant in $\mathbf{D}, \mathbf{G}, \mathbf{J}$, and $\mathbf{M}$ and is particularly clear in the photothrombotic model. Note the strong dendritic staining for the G-CSFR. Original magnification $\times 20$.

G-CSF was given for 5 consecutive days at a dose of $15 \mu \mathrm{g} / \mathrm{kg}$ body weight following photothrombotic induction of ischemia in the sensorimotor cortex. This model has the advantage of producing defined neurological deficits without affecting survival. The dosage chosen is similar to the clinically used regimen in neutropenic patients $(10 \mu \mathrm{g} / \mathrm{kg} / \mathrm{d}$ for up to 14 days).

Sensorimotor deficits were obvious in vehicle-treated ischemic animals compared with sham-operated rats in the rotarod and adhesive tape removal test, and in the neurological severity score (NSS), which included the results of the beam balance test, for up to 6 weeks after the insult (Figure 10, A-D, compare red [ischemia + vehicle] and green [sham]). G-CSF-treated ischemic rats performed significantly better in all test paradigms than vehicletreated animals when group means per time point were compared

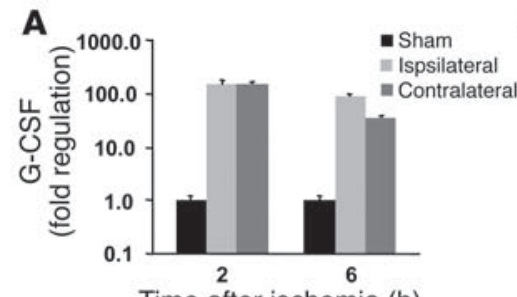

Time after ischemia $(\mathrm{h})$
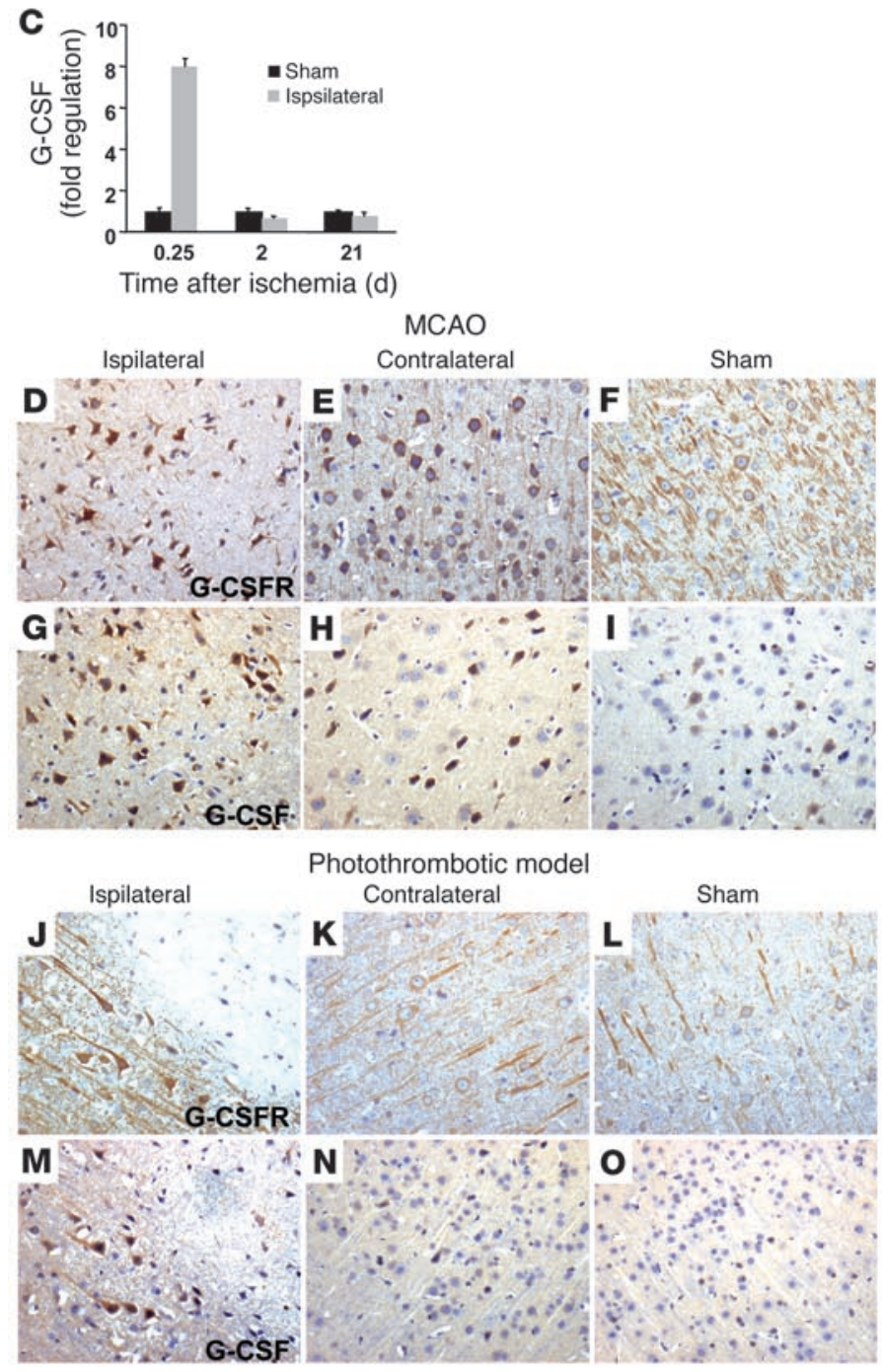

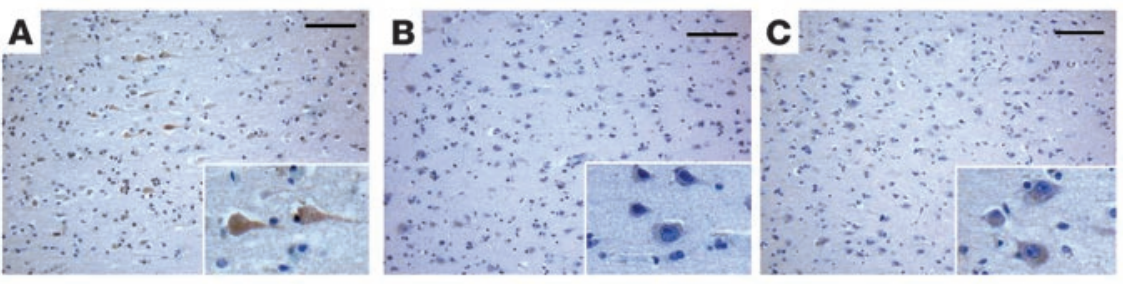

Figure 6

G-CSF receptor is neuronally induced upon human stroke. Immunohistochemical detection of G-CSF receptor in the ipsilateral (A) and contralateral (B) cortex of a human brain obtained at autopsy 3 days after onset of ischemic stroke as well as the frontal cortex of an age-matched neuropathologically normal control brain (C). Scale bars: $100 \mu \mathrm{m}$. Note increased staining of neurons in the ipsilateral cortex compared with the contralateral cortex and control brain (insets).

(Figure 10, A-D, red and blue curves). We also used a statistically more appropriate test for time-series measurements in subjects and compared areas under the individual curves over time (18) (Figure 10, A-D, bar graphs). This analysis also demonstrated a robust behavioral improvement upon G-CSF compared with vehicle treatment (compare red and blue bars). As expected, the performance deficit induced by ischemia in the adhesive tape removal paradigm was more pronounced on the side contralateral to the lesion (Figure 10, C and D; compare red curves). G-CSF induced an improvement of performance both on the contralateral, paretic forepaw and on the ipsilateral extremity (Figure 10, C and D; compare blue versus red curves). However, likely owing to the less pronounced deficit, this difference was only significant for 2 time points on the ipsilateral side but not in the AUC analysis $(P=0.13$; Figure 10D). No difference was noted between shamoperated G-CSF- and vehicle-treated animals (data not shown). Physiological parameters (rectal temperature, $\mathrm{pH}$, partial pressure of $\mathrm{CO}_{2}\left[\mathrm{pCO}_{2}\right], \mathrm{pO}_{2}$, and mean arterial pressure during surgery) did not differ between vehicle- and G-CSF-treated ischemic rats. Also, there were no differences in mortality or body weight among all groups (data not shown). Therefore, G-CSF treatment leads to long-term behavioral improvements after cerebral ischemia.

G-CSF stimulates neural progenitor cells in vivo. We analyzed progenitor cells of the lateral ventricle wall by immunofluorescence against doublecortin (DCX), a microtubule-associated protein that is specifically expressed in neural progenitor cells and immature neurons $(19,20)$. The development into new neurons was detected by

\section{Figure 7}

G-CSF counteracts programmed cell death in rat cortical neurons (A-D) and human neuroblastoma cells (SHSY-5Y) (E) in vitro. (A) The G-CSF receptor is present on primary cortical neurons in culture as shown by immunocytochemistry. (B) G-CSF of both human (h) and mouse $(m)$ origin counteracts camptothecin-induced programmed cell death in primary neurons as determined by caspase-3/7 activity. (C) Preincubation of primary neurons with an antibody against the G-CSF receptor abolishes the antiapoptotic activity of G-CSF (not significant). (D) The NO donor NOR3 [( \pm E) -4-ethyl-2-[(E)-hydroxyimino]-5nitro-3-hexenamide] $(150 \mu \mathrm{M})$ induces apoptosis in primary neurons as evidenced by PARP and caspase- 3 cleavage (immunoblots, first and second lanes), which is reduced by G-CSF treatment (third lane). (E) Also in the human neuroblastoma cell line SHSY-5Y, human or mouse G-CSF reduces caspase activation by the NO donor NOR3. Bar graphs show relative caspase activity levels after normalization to control values. Rel. units, relative units. colabeling of DCX with the mature neuronal marker NeuN (21).

Migration of neuronal progenitor cells from the lateral ventricle wall to the lesioned neocortex has previously been reported (22, 23). When we analyzed the distribution of DCX-expressing cells in the ventricle wall as well as overlying corpus callosum and cortex, we found a visible recruitment of progenitor cells into the ischemic area of the neocortex. This response was visibly enhanced by peripheral infusion of G-CSF (Figure 11, A-I). Area and intensity of DCX immunoreactivity were significantly increased in ischemic G-CSF-treated (ischemia + G-CSF) animals compared with vehicle-treated (ischemia + vehicle) animals (area by $300 \%$ and intensity by $225 \% ; P<0.05$ ). As an indicator of ongoing neuronal differentiation of the DCX-positive cells, coexpression with $\mathrm{NeuN}$ was frequently detected in cells surrounding the lesion site (see Supplemental Figure 6 for Z-stack analysis). However, using BrdU injections during the first 5 days after ischemia to label newly generated cells, we found that BrdU was not incorporated into NeuN-expressing cells in the cortical areas surrounding the lesion site.

The striatum has previously been described to have some degree of progenitor activation and neurogenesis after ischemia due to its proximity to the subventricular pool of neural stem and progeni-
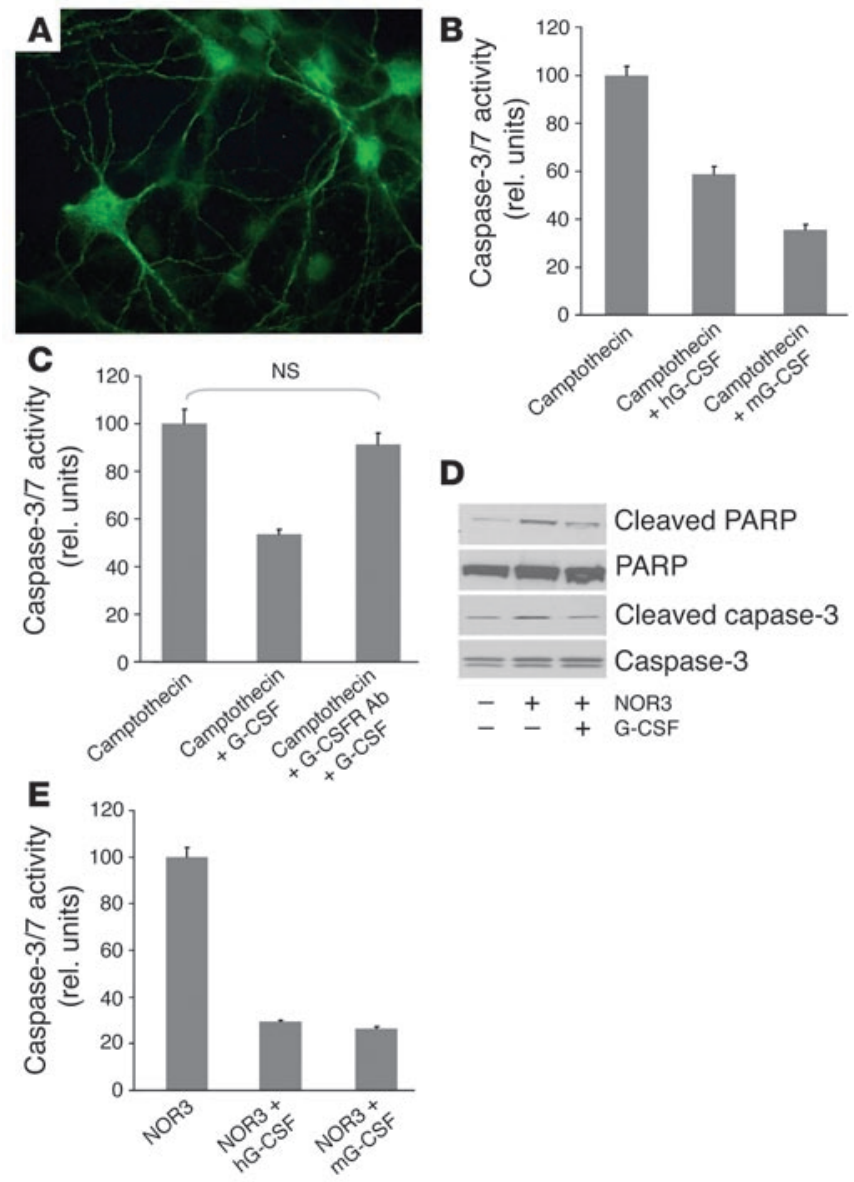

D

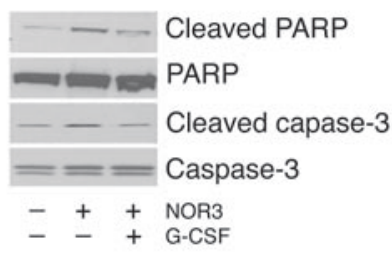


tor cells. We analyzed DCX-positive cells in the striatum at 6 weeks after cortical photothrombosis and peripheral G-CSF infusion. Although the data suggest a trend toward more DCX-positive cells in the striatum of ischemia + G-CSF animals, no significant differences between ischemia + vehicle and ischemia + G-CSF animals were detected (data not shown).

The hippocampus has substantial renewal capacity for granule cells throughout the life of the rat. Since several studies have shown that hippocampal neurogenesis is upregulated after global and focal ischemia $(2,24-27)$, we investigated whether G-CSF treatment would alter the response of dentate gyrus progenitor cells to cortical injury. Using BrdU injections on days 1-5 after cortical photothrombosis, we determined the number of cells positive for BrdU and NeuN (Figure 12, A-E).

When looking at the total number of $\mathrm{BrdU}^{+}$cells in the hippocampus, we noticed an expected strong increase in vehicle-treated animals subjected to cortical photothrombosis on the side of the infarct (ipsilateral + vehicle) but also contralaterally (contralateral + vehicle) (Figure $12 \mathrm{~F}$, compare sham-operated, vehicle-treated [sham + vehicle] with ipsilateral + vehicle and contralateral + vehicle). Although there was a slight increase in $\mathrm{BrdU}^{+}$ cells in the ipsilateral dentate gyrus upon G-CSF treatment (Figure 12F, ipsilateral + vehicle and ipsilateral + G-CSF), this was not statistically significant. However, G-CSF induced a significant rise in newly generated cells in the dentate gyrus in sham-operated animals (Figure 12F, sham + vehicle vs. sham + G-CSF).

Counting NeuN/BrdU-double-positive cells, we found that G-CSF indeed increased the number of newly generated granule cells after ischemia on the side of the lesion (Figure 12G, ipsilateral + vehicle vs. ipsilateral + G-CSF; $P<0.01$ ). In the contralateral (unlesioned) dentate gyrus, the increase in newly generated granule cells after G-CSF treatment was smaller and was not statistically significant (Figure 12G, contralateral + vehicle vs. contralateral + G-CSF). However, G-CSF significantly increased neurogenesis in sham-operated, nonischemic animals (Figure 12G, sham + vehicle vs. sham + G-CSF; $P<0.05)$. Thus, peripheral administration of G-CSF increases hippocampal neurogenesis not only in ischemic animals, but also in the intact, nonischemic rat.

\section{Discussion}

Here we have demonstrated that the hematopoietic factor G-CSF is an endogenous, neuronally expressed ligand that is upregulated upon ischemia and provides protection against programmed cell death in neurons, which is reflected by robust neuroprotective activity in acute stroke models in vivo. In addition, G-CSF displays a strong neurogenic potential in vitro and in vivo, corresponding to long-term behavioral improvements after ischemia.

We found that G-CSF is expressed by neurons in many areas of the CNS, which implies important new functions of this protein in the CNS. This discovery is particularly surprising as G-CSF is a long-known protein that was cloned many years ago as a growth fac- tor in the hematopoietic system (28). To our knowledge, the only reports that suggest expression of G-CSF in neural cell types deal with stimulus-induced expression in astrocyte cultures $(11,29)$. We have therefore carefully examined the cellular origin of G-CSF and could not detect any astrocytic G-CSF expression in vivo, even in the acute cerebral ischemia paradigms studied. It is, however,
A

\section{C}

Time after G-CSF exposure ( $\mathrm{min})$

$\begin{array}{llllll}0 & 20 & 60 & 120 & 240 & 480\end{array}$

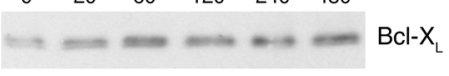

E

Time after G-CSF

$\begin{array}{lllll}0 & 5 & 15 & 30 & 60\end{array}$

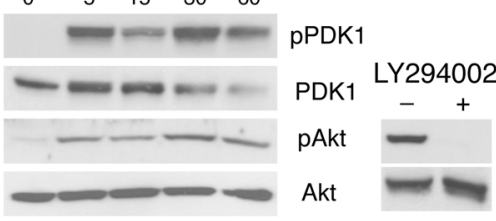

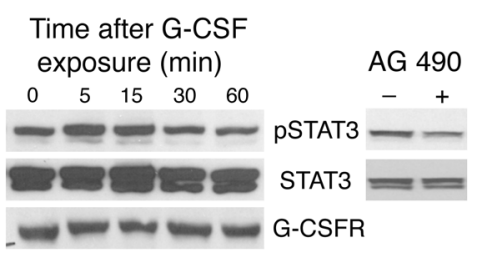

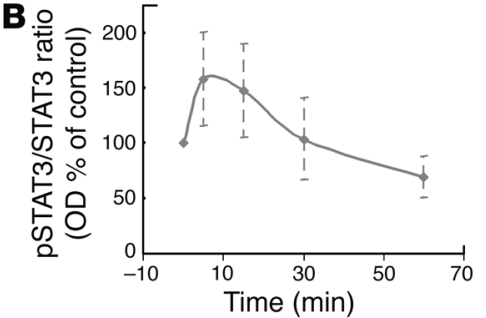

D Time after G-CSF exposure (min) $\begin{array}{lllll}0 & 5 & 15 & 30 & 60\end{array}$
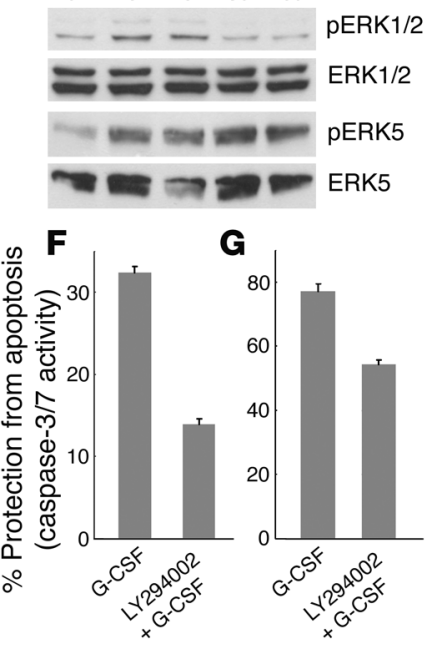

Figure 8

Signal transduction events evoked by G-CSF treatment of rat cortical neurons. G-CSF activates STAT3, ERK, and PI3K/Akt pathways in primary cortical neurons. Western blots for phosphorylated proteins were stripped and reprobed with antibodies nonselective for phosphorylation. (A) STAT3 was rapidly but moderately phosphorylated (pSTAT3) 5 minutes after addition of G-CSF to the medium. Neuronal expression of the G-CSF receptor was also confirmed by Western blot analysis. Addition of the JAK2 inhibitor AG490 inhibited hyperphosphorylation of STAT3 5 minutes after addition of G-CSF. (B) Quantification of phosphorylation ratios from Western blots illustrates the moderate and transient but reproducible activation of STAT3 by G-CSF (data from 3 independent experiments). (C) G-CSF leads to increase of protein levels of the antiapoptotic STAT3 target Bcl- $X_{L}$ in primary cortical neurons over 8 hours. (D) Induction of ERK1/2 (double band) and ERK5 by G-CSF. While ERK1/2 activation appears to be very transient (upper rows), ERK5 is induced for at least 60 minutes following G-CSF exposure (lower rows). (E) Stable induction of Akt phosphorylation upon addition of G-CSF to the medium $(50 \mathrm{ng} / \mathrm{ml})$ shown by immunoblotting with a Ser437 phosphorylation-specific antibody. In accordance with the known Akt activation pathway, the PDK kinase upstream of Akt was phosphorylated, and Akt phosphorylation could be blocked by preincubation of the neurons with the PI3K inhibitor LY294002. (F and G) Inhibition of PI3K by LY294002 diminishes G-CSF-mediated protection from apoptosis (measured by luminometric caspase-3/7 activity assay) in rat cortical neurons treated with staurosporine (F) or in the human neuroblastoma cell line SHSY-5Y, where cell death was elicited by camptothecin $(\mathbf{G})$. Bars indicate mean relative protection (\%) against the cell death stimulus \pm SEM; values were normalized to the appropriate controls ( $n=16$ each). 

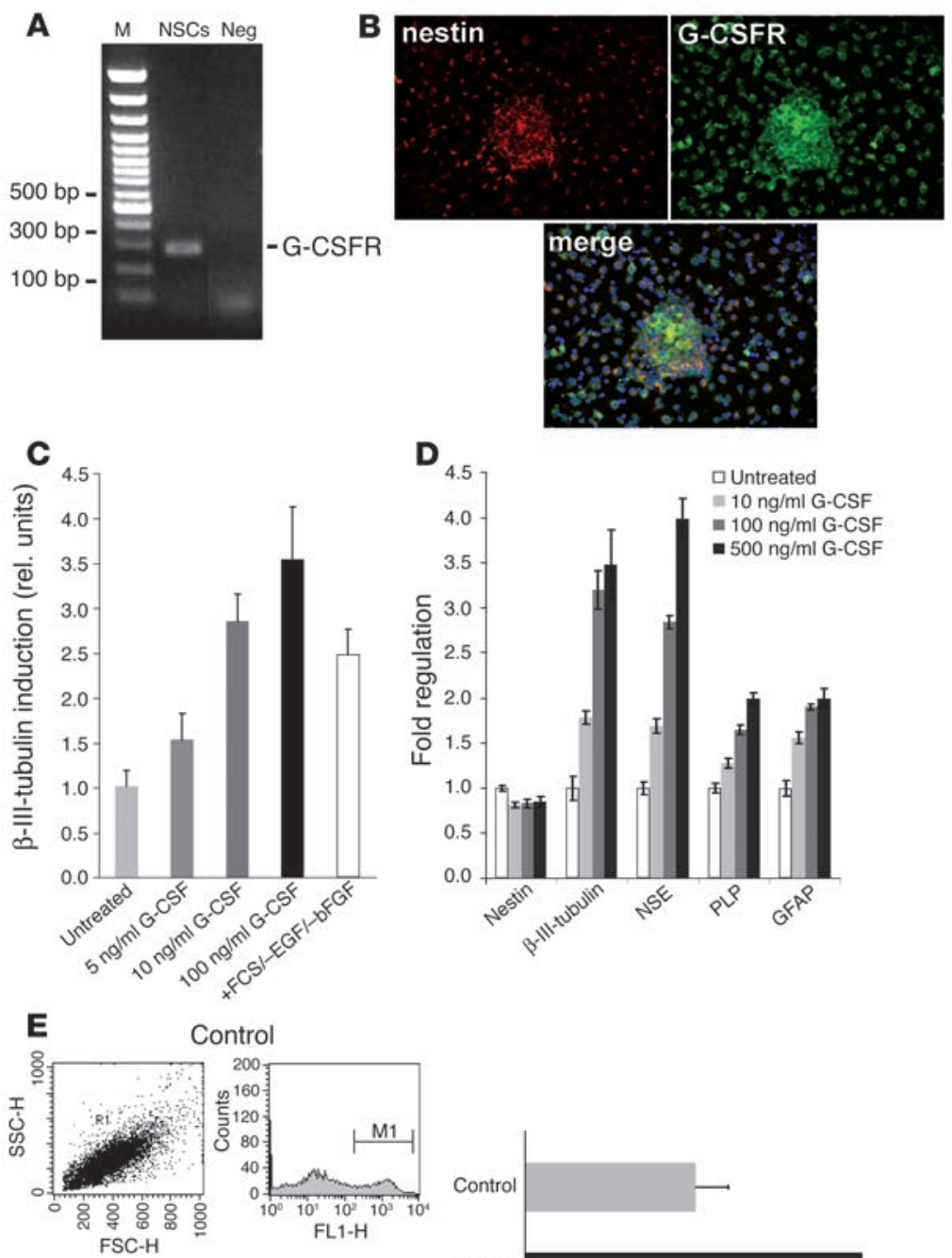

Control
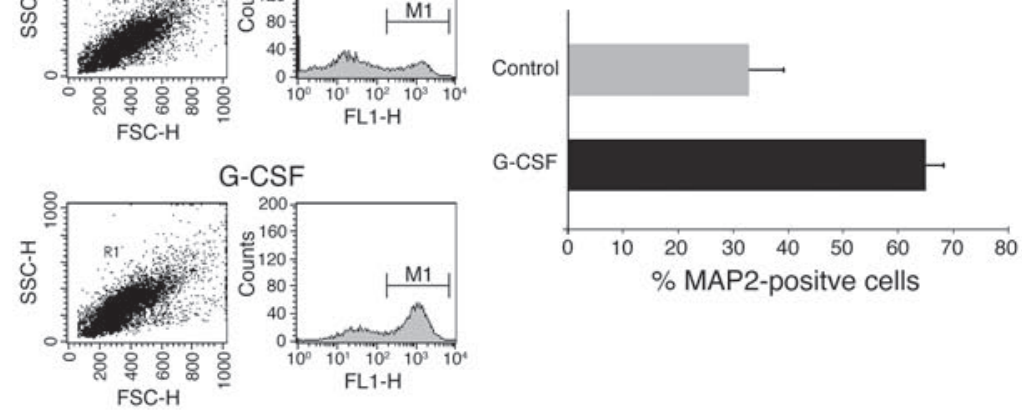

certainly possible that G-CSF expression in astrocytes might be evoked in vivo by other stimuli or occur under different ischemic conditions or at different postischemic time points.

Neuronally expressed G-CSF was induced more than 100-fold at the level of transcription by focal cerebral ischemia. To the best of our knowledge, this is the strongest regulation of any gene by ischemic events in the brain that has been reported so far, implicating an important adaptive response in neurons. In the MCAO model, we found transcriptional induction of this protein early after ischemia in both hemispheres, a phenomenon frequently encountered in this model (30). However, induction became more specific to the ipsilateral hemisphere at 6 hours and was transient, with elevated mRNA levels no longer detectable at 20 hours following ischemia. Importantly, induction was seen not only in focal but also in global ischemic models.

G-CSF's actions in the brain appear to be specifically mediated through the G-CSF receptor, which has an astonishingly

\section{Figure 9}

The G-CSF receptor is present on adult neural stem cells (NSCs) and drives neural progenitor differentiation in vitro. (A) Results of PCR analysis for the G-CSF receptor on neural stem cells demonstrate presence of G-CSF receptor mRNA in neurospheres in culture. (B) Doublefluorescence immunocytochemistry on neural stem cells plated onto coated 96-well plates. Almost all cells were positive for the stem cell marker nestin and for the G-CSF receptor (original magnification, $\times 20$ ). (C-E) G-CSF drives neuronal phenotype induction in adult neural stem cells in vitro. (C) As 1 approach, we assayed $\beta$-III-tubulin promoter activity by a luciferase reporter assay. Treatment with G-CSF in increasing concentrations for 48 hours increased promoter activity. As a positive control, neural stem cells were treated with the standard differentiation protocol involving withdrawal of EGF and bFGF and addition of FCS (+FCS/-EGF/-bFGF). (D) G-CSF treatment induces a concentration-dependent upregulation of the neuronal markers NSE and $\beta$-III-tubulin 4 days after G-CSF treatment, as indicated by quantitative PCR. The glial markers PLP and GFAP are moderately induced in response to increasing G-CSF concentrations. Error bars indicate standard deviations calculated from measurements done with serial dilutions of the cDNA samples $(1: 3,1: 9,1: 27$, and 1:81). (E) FACS analysis for MAP2positive cells served to confirm the data presented above on an individual cell basis. Cells were treated for 4 days prior to analysis. Left: Examples of FACS runs of vehicletreated and G-CSF-treated ( $100 \mathrm{ng} / \mathrm{ml})$ neural stem cells. Right: The bar graph summarizes the results of several experiments (vehicle, $n=4$; G-CSF, $n=7$; $P<0.005$ ).

broad, predominantly neuronal expression pattern in the CNS. Indeed, G-CSF localized to neurons expressing its receptor. Moreover, the G-CSF receptor itself was induced at 6 hours after ischemia. Immunohistochemistry demonstrated a strong induction in the periinfarct zone of both receptor and ligand at this time point. The periinfarct zone is known to harbor neurons at risk of dying, which suggests that G-CSF and its receptor likely function as an autocrine adaptive system in neurons. An autocrine signaling mechanism has indeed been discussed for a number of neuroprotective growth factors in the brain, such as brain-derived neurotrophic factor (BDNF; 31), erythropoietin (EPO; 32), VEGF (33), and neurotrophin-3 (NT-3; 34).

Systemically given G-CSF was able to pass the intact BBB, a property that is shared with other hematopoietic factors such as EPO (35) and GM-CSF (36), and was neuroprotective in 2 different models of focal cerebral ischemia. In vitro, G-CSF displayed strong antiapoptotic activity in neuronal cells. G-CSF evoked very modest and transient activation of STAT3 and ERK1/2 and a strong lasting activation of ERK5, which has recently been implicated in promoting neuronal survival (16). ERK5 was also shown to be activated by G-CSF in non-neural cell types (37). However, the most dramatic effect of G-CSF was seen on the PI3K/Akt pathway, and inhibition of PI3K indeed interfered with the antiapoptotic activity of G-CSF. Since the original description of antiapoptotic activities of Akt in neurons (17), a number of reports have confirmed the powerful central regulatory role of this kinase for neuronal survival (38). In hematopoietic cells, G-CSF activates intracellular 
signaling pathways including STAT3 (39) and Akt (40), which are both linked to suppression of apoptosis and proliferation. Therefore, G-CSF signaling and its role in suppressing apoptosis seem to be preserved both in cells of the hematopoietic lineage and in neurons. The involvement of the antiapoptotic PI3K/Akt pathway in neurons is most likely 1 crucial mechanism for the robust acute infarct volume-reducing effect of G-CSF.

In the hematopoietic system, G-CSF's functions are dual, as they involve inhibition of apoptosis but also differentiation of hematopoietic stem cells. This function seems to be preserved in the CNS, as we found expression of receptor and ligand on adult neural stem cells and induction of a neuronal phenotype in these cells by addition of G-CSF in vitro. G-CSF induced functional recovery, which correlated with increased neuronal progenitor activation in the periphery of the ischemic lesion (cortex and corpus callosum) and with enhanced neurogenesis in the dentate gyrus.

Cortical lesions have previously been reported to enhance neuronal progenitor proliferation in the lateral ventricle wall. Similarly, we have observed that the amount of DCX-positive cells outside the ventricle wall and rostral migratory stream are visibly enhanced in lesioned animals as compared with sham-lesioned controls. We observed an additional increase in the amount of DCX-positive cells under G-CSF treatment that were in close proximity to the lesion site. Although a large number of DCX-positive cells was detected in the immediate periphery of the lesion, the colabeling of BrdU with mature neuronal marker did not indicate substantial maturation of progenitor cells into neurons. Neurogenesis in the lesioned cortex has been reported only by Magavi and colleagues (41), who used a very selective apoptotic elimination of individual cortical neurons, but not by Arvidsson and colleagues (42), who used an MCAO model. Neurogenesis in the striatum was slightly increased after G-CSF treatment, but again the number of newly generated cells was rather small. This corresponds to the findings of Arvidsson et al. that demonstrated that less than $0.2 \%$ of the damaged striatal neuronal population was replaced by newly generated cells after MCAO (42).

The most striking effect of peripherally administered G-CSF on the brain was seen in the dentate gyrus, where G-CSF increased the number of newly generated neurons under ischemic conditions but also in nonischemic, sham-operated animals. It is therefore intriguing to speculate that G-CSF may enhance structural repair and function even in healthy subjects or at long intervals after stroke.

Generation of new differentiated cells from stem cells involves an intricate interplay among proliferation, differentiation, and selective survival. In our in vitro experiments, G-CSF induced neuronal differentiation of adult stem cells without apparently elevating the number of immature stem cells, at least at the time points examined (see Figure 9D). In vivo, the significant increase in hippocampal neurogenesis $\left(\mathrm{BrdU}^{+} / \mathrm{NeuN}^{+}\right.$cells, Figure 12F) was based on the fact that a much higher fraction of $\mathrm{BrdU}^{+}$cells turned into granule cells in ischemic, G-CSF-treated animals compared with ischemic, untreated animals, although the total number of $\mathrm{BrdU}^{+}$cells was unaltered (Figure 12G). This indicates a predominant role of G-CSF in survival and differentiation of progenitor cells in the postischemic brain.

Although more work needs to be done to better understand the balance of effects evoked by G-CSF during neurogenesis in the adult, it is likely that one basic property of G-CSF in neurons, antiapoptosis, also plays a part in the observed neurogenesis. In the hematopoietic system, counteraction of the built-in apoptosis program in progenitor cells by G-CSF is intricately linked to self-renewal and generation of mature cell types of the blood (43). In the neurogenic regions of the adult brain, the majority of proliferative cells are eliminated by apoptosis before reaching a mature phenotype (44-46). Moreover, the involvement of apoptotic signaling in adult hippocampal neurogenesis has been highlighted by a recent study on Bax-deficient mice (47). A combined mechanism of proliferative and survival-promoting effects on adult brain progenitor cells in vivo has indeed been proposed for the action of several other brain- and blood-derived growth factors, such as BDNF and VEGF (48-51).

The cortical photothrombosis model used in this study has the most prominent impact on sensorimotor behavior, which was also measured in the test battery performed, whereas hippocampal formation is most frequently linked to learning and memory processes.

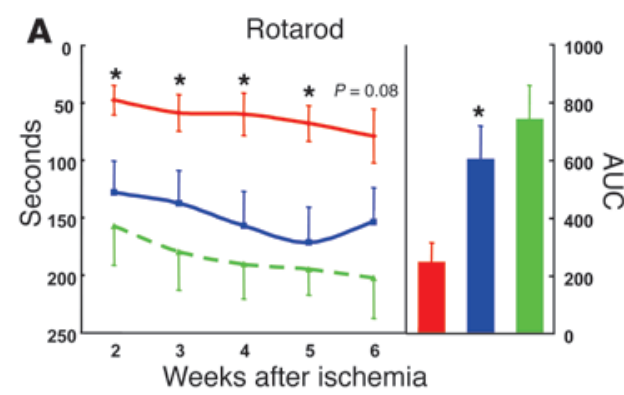

C Adhesive tape removal: contralateral

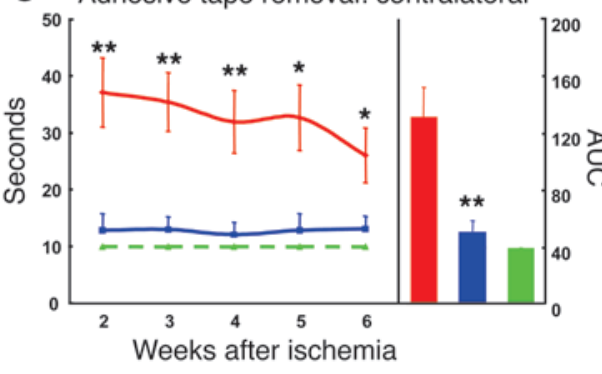

Figure 10

G-CSF treatment improves long-term functional outcome after cortical ischemia. (A-D) G-CSF significantly improved motor recovery as measured by rotarod performance $(\mathbf{A})$ and NSS, which included the results of the beam balance test (B), compared with those in nontreated, ischemic control animals. Sensory-motor function as measured by adhesive tape removal was significantly better in G-CSF-treated, ischemic animals compared with ischemic controls when the contralateral forepaw was tested (C) and borderline significant in the ipsilateral forepaw (D). Bar graphs represent an analysis of area under the curve (AUC) for each rat over time in an experimental group. ${ }^{*} P<0.05 ;{ }^{* *} P<0.01 ;{ }^{\#} P<0.001$. 

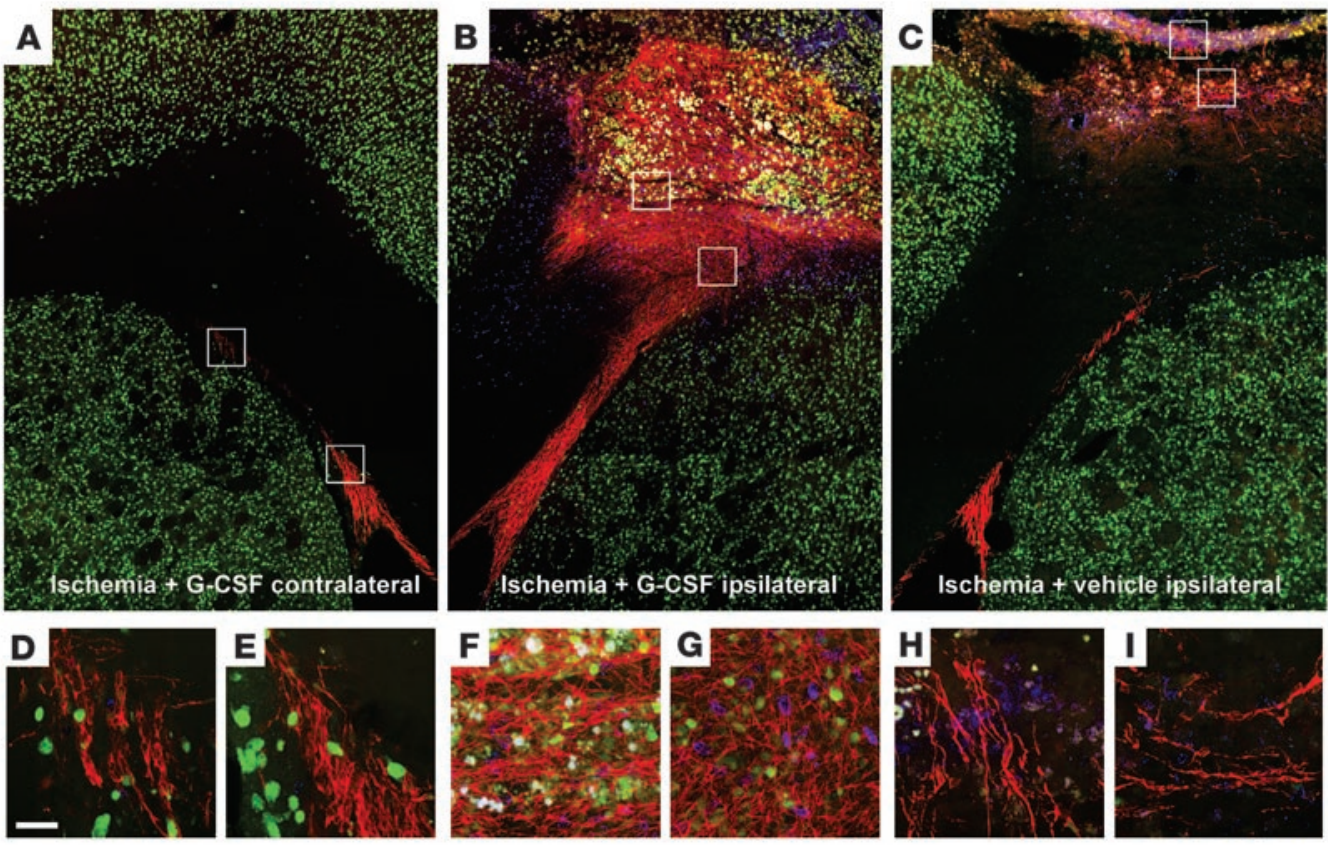

\section{Figure 11}

G-CSF induces neural progenitor cells and their migration in subcortical areas. (A-I) G-CSF induced substantially more neural progenitor cells and immature neurons (DCX in red) in subcortical regions adjacent to the ischemic lesion (NeuN in green, BrdU in blue). (A) Control: unlesioned hemisphere of G-CSF-treated ischemic animals. (B) Lesioned hemisphere with G-CSF treatment. (C) Lesioned hemisphere with sham treatment. Note in B that G-CSF induced a stream of DCX-positive cells migrating toward the ischemic lesion (upper right). (D-I) Details from the boxed areas in A-C. Note the density of DCX expression in F. Images represent cumulative confocal image Z-stacks throughout the whole slice thickness.

However, there is also a wealth of data supporting a possible role of the hippocampus in functional recovery from motor deficits. The hippocampus produces a slow-wave activity known as rhythmical synchronous activity ( $\tau$ rhythm), which is thought to be involved in sensorimotor integration and movement initiation (52-54). Type $1 \tau$ activity gives a direct indication of the level of activation of the motor systems involved in voluntary motor activity, whereas type $2 \tau$ activity indicates the processing of sensory information (52). In the context of our experiments, sensorimotor integration is most crucial to the adhesive-removal paradigm, where the treatment effect of G-CSF was most prominent (see Figure 10C). Cortical lesions have in fact been shown to disrupt the hippocampal $\tau$ activity patterns (55). The connection between the motor system and hippocampal neurogenesis is further supported by the finding that voluntary running is a strong activator of the latter in mice (56-58). We therefore hypothesize that the observed G-CSF-induced increase in hippocampal neurogenesis directly impacts recovery from cortical lesion-induced sensorimotor deficits.

G-CSF signaling appears to be a novel protective system in the brain that is involved in counteracting acute neurodegeneration and regulating the formation of new neurons. G-CSF's principal cellular functions in the CNS appear to be remarkably similar its functions in the hematopoietic system. Thus, G-CSF's basic functions have apparently been conserved and utilized in 2 different body compartments. While the direct actions of G-CSF uncovered here appear sufficient to fully explain the observed in vivo effects of this protein, it is certainly possible that additional mechanisms such as the mobilization of bone marrow stem cells have a role in G-CSF-mediated neuroprotection, although proof for this hypothesis is lacking at present $(59,60)$. We have concentrated here on examining the effects of G-CSF in vivo by using the most clinically relevant application scheme of peripheral administration. For the further dissection of mechanisms of action, and to study the role of brain-endogenous G-CSF, studies with transgenically modified mice, such as neuronspecific knock-outs for the G-CSF receptor, are warranted.

In therapeutic terms, G-CSF fulfills the criteria of a novel type of stroke drug discussed in the introduction. Its multimodality, together with the ability to penetrate the BBB and its documented history as a well-tolerated drug, make G-CSF an ideal drug candidate for treatment of stroke. Our data suggest a comparable functionality of the neural G-CSF system in the human. First, the G-CSF receptor is neuronally expressed in the human brain in a pattern of distribution similar to that in rodents. Second, a human neuroblastoma line expresses the receptor and is protected against programmed cell death. Finally, the G-CSF receptor is induced in the ipsilateral infarcted cortex shortly after stroke. We have therefore started a phase IIa trial to establish the safety of i.v. administered G-CSF in acute stroke patients.

The broad expression of the G-CSF receptor in many brain areas, the passage of G-CSF through the intact $\mathrm{BBB}$, the effect on neurogenesis in the nonischemic animal, and the favorable tolerance profile suggest that G-CSF might be beneficial for a number of other neurodegenerative and psychiatric disorders in which neuronal cell death and/or disturbances in neurogenesis are involved.

\section{Methods}

\section{Ischemic models}

Intraluminal occlusion model. Animals received inhalation anesthesia with $70 \% \mathrm{~N}_{2} \mathrm{O}, 30 \% \mathrm{O}_{2}$, and $1 \%$ halothane. The femoral artery was cannulated 
for recording of continuous arterial blood pressure and blood sampling for gas analyses. The right femoral vein was used for drug delivery. During the experiment, core body temperature was monitored and maintained at $37^{\circ} \mathrm{C}$ by a thermostatically controlled heating pad (FMI GmbH). MCAO was induced with a silicon-coated (Provil Novo; Heraeus Kulzer) 4-0 nylon filament (ETHICON) that was introduced into the common carotid artery (CCA) and advanced into the internal carotid artery as described previously (9). Successful MCAO was verified by laser Doppler flowmetry (Perimed 4000 ) with a probe positioned $4 \mathrm{~mm}$ posterior to the bregma and $4 \mathrm{~mm}$ lateral from the midline. After 90 minutes MCAO, the filament was withdrawn to allow for reperfusion. Two hours after onset of occlusion, $60 \mu \mathrm{g} / \mathrm{kg}$ G-CSF (NEUPOGEN; Amgen Inc.) was infused i.v. over 20 minutes. Infarct volumes were determined by 2,3,5-triphenyl tetrazolium chloride (TTC) staining as described previously (9). Two-millimeter sections were cut using a brain matrix (Harvard Apparatus) and stained with TTC (Sigma-Aldrich) for 10 minutes at $37^{\circ} \mathrm{C}$. Stained sections were scanned on both sides using a color scanner and infarct areas determined using ImageJ version $1.32 \mathrm{j}$ (http://rsb.info.nih.gov/ij). Edema correction was performed as described previously (9). For the MCAO model, animals with no or minimal infarcts $\left(<60 \mathrm{~mm}^{3}\right)$ were excluded from the analysis before unblinding

Combined CCA/distal middle cerebral artery occlusion model. Transient left combined CCA/middle cerebral artery (CCA/MCA) occlusion model was achieved as described previously (10). Briefly, animals fasted overnight were anesthetized with chloral hydrate $(0.45 \mathrm{~g} / \mathrm{kg}$ i.p.). The right femoral vein and artery were cannulated for recording of arterial blood pressure and drug administration. Core body temperature was maintained at $36.5 \pm 0.5^{\circ} \mathrm{C}$ during ischemia and the first hour of reperfusion through the use of a feed-forward temperature controller. The ipsilateral CCA was isolated and tagged through a ventral, cervical midline incision. A 0.005 inch-diameter stainless steel wire (Small Parts Inc.) was placed underneath the left MCA rostral to the rhinal fissure, proximal to the major bifurcation of the MCA, and distal to the lenticulostriate arteries. The artery was then lifted, and the wire was rotated clockwise to ensure occlusion. The CCA was next occluded with an atraumatic aneurysm clip. Cerebral perfusion at the cortical surface, $3 \mathrm{~mm}$ distal to the locus of the MCAO, was measured with a laser Doppler flowmeter (LDF) (model BPM2; Vasamedic). Only those ani-

\section{Figure 12}

G-CSF increases neurogenesis in the dentate gyrus. (A) Example of BrdU/NeuN-double-positive cells within the basal layer of the dentate gyrus (scale bar: $40 \mu \mathrm{m}$ ). The arrow in $\mathbf{A}$ indicates the enlarged double-stained cell in $\mathbf{B}$ (scale bar: $10 \mu \mathrm{m}$ ). (C) DCX in red. (D) BrdU in green. (E) NeuN in blue. (F) G-CSF increased the number of newly generated neurons $\left(\mathrm{BrdU}^{+} / \mathrm{NeuN}+\right)$ on the side of the ischemic lesion (red bars, ipsilateral + vehicle vs. ipsilateral + G-CSF; ${ }^{* *} P<0.01$ ). Contralateral to the lesion, there was a trend toward an increase in newly generated neurons compared with vehicle-treated ischemic animals that was not statistically significant (blue bars, contralateral + vehicle vs. contralateral + G-CSF). However, G-CSF increased neurogenesis in sham-operated, nonischemic animals (green bars, sham + vehicle vs. sham + G-CSF; $\left.{ }^{*} P<0.05\right)$. (G) The total number of $\mathrm{BrdU}^{+}$cells in the dentate gyrus was not significantly further increased by G-CSF treatment in the ischemic animals (red and blue bars), which implies a true induction of neuronal differentiation by G-CSF in the postischemic brain. In contrast, sham-lesioned animals showed an elevation of the total number of BrdU+ cells after G-CSF treatment (green bars; ${ }^{*} P<0.05$ ). mals that displayed a cerebral perfusion of $10-15 \%$ of the initial value on the LDF scale (expressing relative values of cerebral perfusion) were included in the study. G-CSF $(50 \mu \mathrm{g} / \mathrm{kg})$ was infused i.v. over 20 minutes starting 60 minutes after induction of ischemia. After 180 minutes of combined CCA/distal MCA occlusion model, reperfusion was established through reversal of the occlusion procedure. After 72 hours of reperfusion, animals were reanesthetized and transcardially perfused with $50 \mathrm{ml}$ of saline. Perfused isolated brains were transferred into ice-cold PBS for sectioning. Infarct volumes were determined by TTC staining (see above).

Photothrombotic ischemia model. Male Wistar rats weighing 280 to $320 \mathrm{~g}$ were anesthetized with an intramuscular injection of $100 \mathrm{mg} / \mathrm{kg}$ body weight ketamine hydrochloride (Ketamin 2; Medistar Arzneimittelvertrieb $\mathrm{GmbH}$ ) and $8 \mathrm{mg} / \mathrm{kg}$ body weight xylazine hydrochloride (Rompun; Bayer). Anesthesia was maintained with administration of $50 \mathrm{mg} / \mathrm{kg}$ body weight ketamine hydrochloride and $4 \mathrm{mg} / \mathrm{kg}$ body weight xylazine hydrochloride if necessary. A PE-50 polyethylene tube was inserted into the right femoral artery for continuous monitoring of mean arterial blood pressure and blood gases. The right femoral vein was cannulated by a PE-50 tube for treatment infusion. During the experiment, rectal temperature was monitored and maintained at $37^{\circ} \mathrm{C}$ by a thermostatically controlled heating pad (FMI $\mathrm{GmbH})$. Photothrombotic ischemia was induced in the rat parietal cortex according to the method of Watson et al. (61). Animals were placed in a stereotaxic frame, and the scalp was incised for exposure of the skull surface. For illumination, a fiber-optic bundle with a $1.5-\mathrm{mm}$ aperture was placed stereotaxically onto the skull $4 \mathrm{~mm}$ posterior to the bregma and $4 \mathrm{~mm}$ lateral from the midline. The skull was illuminated with a cold, white light beam $(150 \mathrm{~W})$ for 20 minutes. During the first 2 minutes of illumination, the dye rose bengal $(0.133 \mathrm{ml} / \mathrm{kg}$ body weight, $10 \mathrm{mg} / \mathrm{ml}$ saline $)$ was injected i.v. Sham-operated animals underwent the same experimental procedures as described above without infusion of rose bengal and illumination. After surgery, the catheters were removed, and the animals were allowed to recover from the anesthesia and given food and water ad libitum. For treatment,
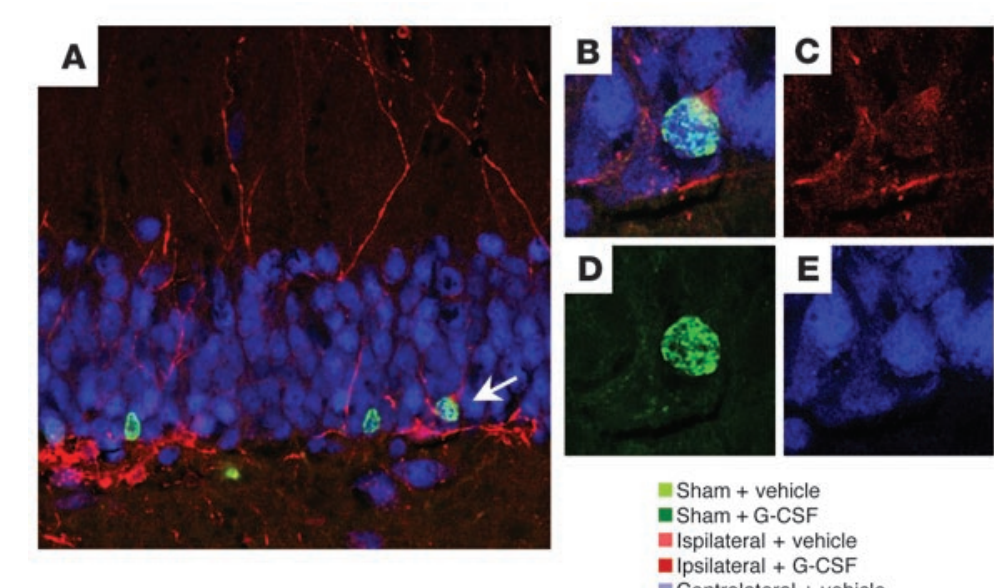

ESham + vehicle - Sham + G-CSF Ispilateral + vehicle - Ipsilateral + G-CSF Contralateral + vehicle nContralateral + G-CSF
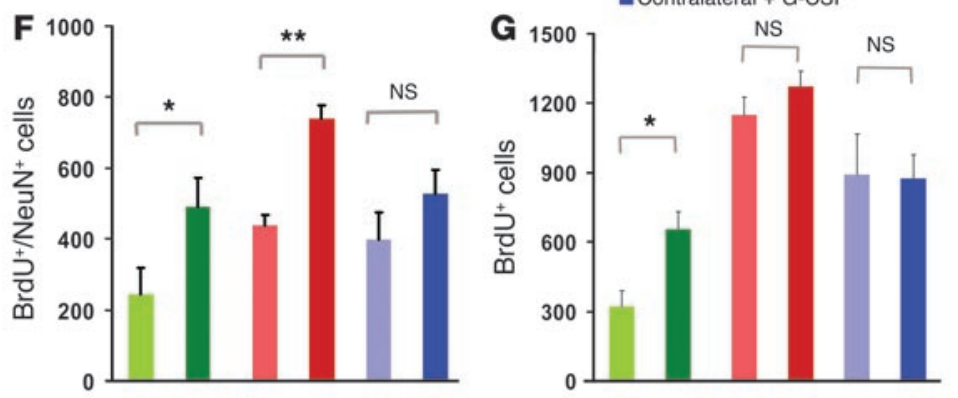
ischemic or sham-operated animals were given $15 \mu \mathrm{g}$ G-CSF $/ \mathrm{kg}$ body weight i.v. or vehicle 1 hour after the procedure. Daily repeated i.v. bolus infusions via the tail vein (G-CSF or vehicle) followed on days 2-5. Four hours after each tail vein injection of G-CSF or vehicle on days $1-5$, dividing cells were labeled with BrdU by i.p. injections $(50 \mathrm{mg} / \mathrm{kg} / \mathrm{d})$. We perfused animals 37 days after the last injection in order to histologically assess the amount of progenitor cells and newly generated neurons.

All animal experiments were performed in accordance with national and international regulations and were approved by the Regierungspräsidium Karlsruhe (Karlsruhe, Baden-Württemberg, Germany) and the Animal Welfare Committee of the University of Texas - Houston (Houston, Texas, USA). All experiments were done in a fully randomized and blinded fashion.

\section{Behavioral measurements}

Combined CCA/distal MCA occlusion model. All sensorimotor tests were performed during the light cycle between morning and early afternoon. Animals were tested at 72 hours just before they were killed for infarct volume determination. Testing was performed by an investigator blinded to the experimental groups. A neurological deficit score (0 to 18) was calculated by combining the scores of the following 4 tests: forelimb placing (both whisker and forward), foot-fault, and cylinder tests. Tests were done as described in detail in ref. 62 .

Photothrombotic model. In all animals, a battery of behavioral tests was performed during the light cycle before ischemia after a training period of 3 days and at 2, 3, 4, 5, and 6 weeks after ischemia by an investigator blinded to the experimental groups. Tests such as the rotarod, adhesive tape removal, and beam balance were done as described in detail in ref. 63 . NSS was modified according to ref. 64. Neurological function was graded on a scale of 0 to 16 (normal score, 0 ; maximal deficit score, 16). NSS is a composite of motor, sensory, and reflex tests and includes the beam balance test (65). In the NSS, 1 score point is awarded for the inability to perform the test or for the lack of a tested reflex; thus, the higher the score, the more severe the injury.

\section{$B B B$ passage}

G-CSF and BBB-impermeable BSA (control) were radiolabeled with ${ }^{131} \mathrm{I}$ (Amersham Biosciences) by the 1,3,4,6-tetrachloro-3 $\alpha, 6 \alpha$-diphenylglycouril (Iodo-Gen; Pierce) method (66) and purified on Sephadex G-25 (Amersham Biosciences) columns. The radiolabeled proteins were injected via the tail vein of nonischemic female Sprague-Dawley rats (250-300 g). After 1, 4, and 24 hours following injection of substances, animals were terminally anesthetized with Rompun/Ketanest and perfused carefully with HBSS, and the whole brain was dissected, blotted dry, and weighed. Blood was centrifuged to obtain the serum. The radioactivity was measured with a gamma counter (LB 951G; Berthold Technologies GmbH) along with a sample of the injection solution to calculate the percent of injected dose per gram of the tissues.

\section{Histology}

During deep anesthesia, animals were transcardially perfused with $4 \%$ paraformaldehyde, and brains were removed and either prepared as freefloating cryosections $(40 \mu \mathrm{m})$ or embedded in paraffin. For G-CSF or G-CSF receptor immunohistochemistry, sections of paraffin-embedded tissues $(2 \mu \mathrm{m}$ ) were deparaffinized and microwaved (in citrate buffer at 500 $\mathrm{W}$ for 10 minutes). Afterwards, sections were incubated at room temperature with the respective antisera (1:500; Santa Cruz Biotechnology Inc.) for 1 hour in a humid chamber. Staining was visualized using the avidinbiotin complex $(\mathrm{ABC})$ technique with $\mathrm{DAB}$ as chromogen (DakoCytomation). For double immunofluorescence, sections were incubated with the G-CSF receptor antiserum (1:100), and following incubation with an anti- rabbit FITC-conjugated secondary antibody (1:200; Dianova), either the G-CSF (1:100), GFAP, or NeuN antisera (1:100; Chemicon International) were applied. For detection, the sections were incubated with an appropriate TRITC-conjugated secondary antibody (1:200; Dianova), and nuclear staining was performed using DAPI. For negative controls, the primary antiserum was omitted. All double-fluorescence experiments were controlled by parallel single stainings and checked for any fluorescence crosstalk between detection channels. Double-fluorescence stainings were also performed with switched chromophores for the secondary antibody.

\section{Human autopsy samples}

Formaldehyde-fixed, paraffin-embedded brain tissue samples from a patient suffering from acute ischemic stroke within the anterior circulation as well as an age- and sex-matched control were obtained from routine autopsy cases. Permission for storage and use of human autopsy tissue was obtained from the Ethikkommision der Medizinischen Fakultät der Universität Münster in Münster, Germany. Clinical records, autopsy reports, as well as radiological findings were reviewed in order to determine onset of neurological symptoms and to exclude malignancy, hematological disorders, sepsis or concomitant neurological disease. The 81-year-old female stroke patient had died 3 days upon documented onset of neurological symptoms due to progressive brain edema. The control patient (female, 82 years old) had died upon acute gastrointestinal bleeding. The intervals between death and autopsy were 67 hours and 56 hours, respectively. After antigen retrieval (boiling in $10 \mathrm{mM}$ citrate buffer, $\mathrm{pH}$ 6), sections from the ipsilateral and contralateral cortex (stroke patient) or frontal cortex (control) were stained using specific antibodies against the G-CSF receptor (1:100; Santa Cruz Biotechnology Inc.), appropriate secondary antibodies, and the $\mathrm{ABC}$ technique using an automated staining system (TechMate; DakoCytomation).

\section{Immunocytochemistry}

Neural stem cells were dissociated and plated on poly-L-ornithin/laminin-coated 96-well plates at a density of 30,000 cells/well. After 2 days, stem cells were washed with PBS (Invitrogen Corp.) $\left(37^{\circ} \mathrm{C}\right)$ and fixed with $4 \%$ paraformaldehyde for 10 minutes on ice. Then cells were washed with PBS $\left(4^{\circ} \mathrm{C}\right)$ and stored at $4^{\circ} \mathrm{C}$. Cells were incubated for 10 minutes in 50 $\mathrm{mM}$ glycine in PBS and then washed with PBS. After permeabilization on ice using $0.2 \%$ Triton X-100 (Sigma-Aldrich) in PBS, cells were incubated with blocking solution (1\% BSA in PBS) at room temperature. The G-CSF receptor antiserum (1:100; Santa Cruz Biotechnology Inc.) and the nestin antiserum (1:100; BD Transduction Laboratories) were incubated over night at $4{ }^{\circ} \mathrm{C}$. Cells were then washed with $0.1 \% \mathrm{BSA}$ in PBS and incubated for 1 hour with the secondary antibodies (anti-rabbit FITC and anti-mouse TRITC, 1:200; Dianova) at room temperature. Cells were then washed briefly in $0.1 \%$ BSA in PBS and stained with Hoechst 33342 (Invitrogen Corp.) (1:10,000 in PBS).

\section{In situ bybridization}

Riboprobes were generated from PCR-generated templates of cloned human G-CSF cDNA using T7 (antisense probe) or T3 (sense probe) polymerase (Roche Diagnostics Corp.). Transcripts were labeled with rUTP-biotin. Specificity and concentration of transcripts were verified by denaturing PAGE. Two-micrometer paraffin sections were deparaffinized, prehybridized (50\% formamide; $1 \%$ sarcosyl; $0.02 \%$ SDS; $5 \times$ SSC; $2 \times$ washing reagent from the DIG Wash and Block Buffer Set [Roche Diagnostics Corp.]), partially digested with proteinase $\mathrm{K}$, washed with $0.1 \mathrm{M}$ glycine/ PBS, and incubated with $500 \mathrm{ng} / \mathrm{ml}$ probe overnight at $60^{\circ} \mathrm{C}$. Sections were washed, RNAse A treated (buffer: 5 mM Tris- $\mathrm{HCl}, \mathrm{pH}$ 8.0; $250 \mathrm{mM} \mathrm{NaCl}$; $0.5 \mathrm{mM}$ EDTA), and incubated for 2 hours with Streptavidin-AP (Roche Diagnostics Corp.), and stainings were developed using nitro blue tetra- 
zolium chloride and 5-bromo-4-chloro-3-indolyl phosphate, toluidine salt (NBT/BCIP) in detection buffer (100 mM Tris-HCl, pH 9.5; $100 \mathrm{mM}$ $\mathrm{NaCl} ; 50 \mathrm{mM} \mathrm{MgCl}_{2}$ ) overnight at room temperature. Sections were counterstained using hemalum and photographed digitally (Olympus IX70). Sense controls did not yield any specific staining.

\section{Detection of G-CSF mRNA in microdissected cells}

Horizontal cryostat brain sections $(8 \mu \mathrm{m})$ were prepared from mouse brain and were mounted on frame slides (POL-membrane, $0.9 \mu \mathrm{m}$; Leica Microsystems). Sections were stained with Alexa 488-conjugated NeuN or GFAP antibodies (Chemicon International) using a rapid immunohistochemistry protocol. Identified single neurons or astrocytes were isolated from the frontal cortex using laser microdissection (Leica). One hundred cells were pooled in $75 \mu \mathrm{l}$ RNA lysis buffer (QIAGEN) and stored at room temperature until further processing. RNA was isolated using the RNeasy Micro Kit (QIAGEN). RNA quality and quantity were checked by analyzing $1 \mu \mathrm{l}$ of RNA on the Agilent 2100 Bioanalyzer using the RNA 6000 Pico LabChip Kit (Agilent Technologies). T7-RNA polymerase-mediated linear amplification was performed according to optimized protocols for lowinput RNA amounts. Briefly, after first- and second-strand cDNA synthesis, RNA was transcribed with the T7 MEGAscript Kit (Ambion Inc.) at $37^{\circ} \mathrm{C}$ for 16 hours. Amplified antisense RNA was purified with the RNeasy Mini Kit (QIAGEN) and precipitated. First-strand cDNA was synthesized using random primers, which was followed by second-strand synthesis. PCR was performed for cyclophilin B (mm-cycB1s, TTGCTGCAGCCATGGTCAAC; mm-cycB1as, ATTCAGTCTTGGCAGTGCAG, product length $371 \mathrm{bp}$ ), GFAP (mGFAPs, CCCCATCCGCTCAGTCATCTTACC; mGFAPas, TGTCTTCCCTACCTGCCCACCAAT, product length $280 \mathrm{bp}$ ), and G-CSF (GCSF-790s, GGAGCTCTAAGCTTCTAGATC; GCSF-1154as, TAGGGACTTCGTTCCTGTGAG, product length $364 \mathrm{bp}$ ) under the following conditions: GFAP and cyclophilin were amplified over 30 cycles at an annealing temperature of $60^{\circ} \mathrm{C}$; G-CSF was amplified over 50 cycles at an annealing temperature of $64^{\circ} \mathrm{C}$. As a positive control, a brain-specific plasmid library was used. Products were visualized by agarose gel electrophoresis and ethidium bromide staining.

\section{Primary neuronal cultures}

Ten to 12 cortices or hippocampi were dissected from Wistar rat embryos on E18. The tissue was dissociated using $10 \mathrm{mg} / \mathrm{ml}$ trypsin, $5 \mathrm{mg} / \mathrm{ml}$ EDTA/DNase (Roche Diagnostics Corp.) in HBSS (BioWhittaker Molecular Applications). The digestion was stopped using 4 parts neurobasal medium containing $1 \times$ B-27 supplement (Invitrogen Corp.), $0.5 \mathrm{mM}$ L-glutamine, and $25 \mu \mathrm{M}$ glutamate. After centrifugation, the cell pellet was dissolved in $5 \mathrm{ml}$ medium and plated at a density of 250,000 cells per well of a 24-well-plate on glass coverslips coated with poly-L-lysine (for immunocytochemistry or Western blot analyses) or into 96-well plates at $5 \times 10^{4}$ cells /well (for cell death assays).

\section{Caspase activity assays}

For caspase-3/7 assays, we used the human neuroblastoma cell line SHSY-5Y or rat primary cortical neurons. Cells were seeded into 96-well plates $\left(5 \times 10^{4}\right.$ cells $/$ well) for 2 (SHSY-5Y) or 14-21 days (neurons). To elicit programmed cell death, we treated cells with either the NO donor NOR3 [( \pm E)-4-ethyl-2-[(E)-hydroxyimino]-5-nitro-3-hexenamide] (SigmaAldrich) at $150 \mu \mathrm{M}, 1 \mu \mathrm{M}$ staurosporine, or $20 \mu \mathrm{M}$ camptothecin (both Merck-Calbiochem) for 5 hours with or without recombinant human (NEUPOGEN; Amgen Inc.) or murine (R\&D Systems) G-CSF at $50 \mathrm{ng} / \mathrm{ml}$. For receptor blocking experiments, primary cortical neurons from the rat were preincubated for 1 hour with $1 \mu \mathrm{g} / \mathrm{ml}$ anti-G-CSF receptor antibody (SC 9173; Santa Cruz Biotechnology Inc.) and then treated with $20 \mu \mathrm{M}$ camptothecin to induce apoptosis. G-CSF was added to a final concentration of $50 \mathrm{ng} / \mathrm{ml}$. Incubation was continued for 5 hours, and caspase-3/7 activity was determined by the Caspase-Glo Assay (Promega). For inhibition of PI3K, the inhibitor LY294002 (Merck-Calbiochem) was added at $50 \mu \mathrm{M}$ final concentration 30 minutes prior to cell death stimuli and G-CSF. Caspase-3/7 activity was determined after 5 hours by the CaspaseGlo Assay (Promega), and luminescence measured with a plate reader (Mithras; Berthold Technologies GmbH). Eight to 16 independent data points were generated for each treatment.

\section{Western blots analyses}

For time series pathway analyses, rat primary cortical neurons (21 days in vitro [DIV]) were treated with G-CSF (NEUPOGEN; Amgen Inc.) and harvested at 5, 15, 30, and 60 minutes. Experiments were repeated at least twice with independent preparations of neurons. For determination of PARP cleavage, neurons (21 DIV) were treated with $150 \mu \mathrm{M}$ NOR3 with or without G-CSF $(50 \mathrm{ng} / \mathrm{ml})$. Primary neurons were scraped off the plate and washed twice in ice-cold PBS containing $2.5 \mathrm{mg} / \mathrm{ml}$ pepstatin (Sigma-Aldrich) and aprotinin (1:1,000; Sigma-Aldrich). Pellets were resuspended in 1 volume 2\% SDS (40 $\mu \mathrm{l}$ ), and $5 \mu \mathrm{l}$ Benzonase solution ( $40 \mu \mathrm{l} 100 \mathrm{mM} \mathrm{MgCl}_{2}$ and $9 \mu \mathrm{l}$ Benzonase; Roche Diagnostics Corp.) was added. After solubilization, 1 volume PBS was added and the protein concentration determined (BCA Protein Assay; Pierce). After denaturing at $95^{\circ} \mathrm{C}$ for 5 minutes, $100 \mu$ g were run on $8 \%$ SDS-polyacrylamide gels. Proteins were transferred onto nitrocellulose membranes (Protan BA79; Schleicher \& Schuell) using a semi-dry blotting chamber (Whatman Biometra). Blots were blocked with $5 \%$ milk powder in PBS $/ 0.02 \%$ Tween-20, washed 3 times with PBS/0.02\% Tween-20, and incubated for 1 hour at room temperature with the primary antibody (anti-cleaved PARPantibody, 1:1000 [Cell Signaling Technology]; anti-Bcl-2 antibody, 1:500 [BD Transduction Laboratories]; anti-STAT3 and anti-phosphorylated STAT3 antibodies, 1:500 [Cell Signaling Technology]; all other antibodies were from Cell Signaling Technology). After washing, the blots were incubated with the secondary antibody (anti-rabbit antiserum HRP-coupled or anti-mouse antiserum HRP-coupled, 1:4,000; Dianova) for 1 hour at room temperature. Signals were detected using the SuperSignal chemiluminescence system (Pierce) and exposed to Hyperfilm-ECL (Amersham Biosciences). Intensities of bands for phosphorylated Stat 3 and Stat 3 were quantified on scanned autoradiographs using Windows ImageJ version 1.29.

\section{Quantitative PCR analysis}

RNA of brains was isolated using the acidic phenol extraction protocol followed by QIAGEN RNeasy Mini Kit purification according to the manufacturer's recommendations. cDNA was synthesized from $5 \mu \mathrm{g}$ total RNA using oligo-dT primers and Superscript II Reverse Transcriptase (Invitrogen Corp.). Quantitative PCR analysis was performed using the LightCycler system (Roche Diagnostics Corp.) with SYBR green staining of DNA double strands. Cycling conditions were as follows: 5 minutes at $95^{\circ} \mathrm{C}, 5$ seconds at $95^{\circ} \mathrm{C}, 10$ seconds at $66^{\circ} \mathrm{C}, 30$ seconds at $72^{\circ} \mathrm{C}, 10$ seconds at $84^{\circ} \mathrm{C}$ for 50 cycles. Melting curves were determined using the following parameters: $95^{\circ} \mathrm{C}$ cooling to $50^{\circ} \mathrm{C}$; ramping to $99^{\circ} \mathrm{C}$ at $0.2^{\circ} \mathrm{C} /$ second. The following primer pairs were used: rat G-CSFR-frag-32s, CCATTGTCCATCTTGGGGATC; rat G-CSFR-frag-265as, CCTGGAAGCTGTTGTTCCATG; G-CSF-345s, CACAGCGGGCTCTTCCTCTACCAA; G-CSF-862as, AGCAGCGGCAGGAATCAATACTCG. The LightCycler PCR analysis was performed using the SYBR Green master mix, according to the manufacturer's recommendations (Roche Diagnostics Corp.). Specificity of product was ensured by melting point analysis and agarose gel electrophoresis. cDNA content of samples was normalized to the expression level of cyclophilin (primers: cyc5, ACCCCACCGTGTTCTTCGAC; асус300, CATTTGCCATGGACAAGATG). Relative regulation levels were derived after normalization to cyclophilin. 


\section{Neurogenesis detection in vivo}

Progenitor activity and neurogenesis were visualized by immunofluorescence as previously described $(44,67)$, but a brief description is given below. The following antibodies were used: rat anti-BrdU (1:500; Accurate Chemical $\&$ Scientific Corp.), mouse anti-NeuN (1:500, Chemicon International), goat anti-DCX C-18 (1:500; Santa Cruz Biotechnology Inc.), anti-rat FITC, anti-goat rhodamine $\mathrm{X}$, anti-mouse Cy5 (Jackson ImmunoResearch Laboratories Inc.). Free-floating sections were treated with $0.6 \% \mathrm{H}_{2} \mathrm{O}_{2}$ in Trisbuffered saline (TBS: $0.15 \mathrm{M} \mathrm{NaCl}, 0.1 \mathrm{M}$ Tris- $\mathrm{HCl}, \mathrm{pH} 7.5$ ) for 30 minutes. BrdU-labeled nuclei were detected by immunofluorescence after DNA denaturation: 2 hours incubation in $50 \%$ formamide $/ 2 \times$ SSC $(2 \times$ SSC: 0.3 $\mathrm{M} \mathrm{NaCl}, 0.03 \mathrm{M}$ sodium citrate) at $65^{\circ} \mathrm{C}, 5$ minutes rinse in $2 \times \mathrm{SSC}, 30$ minutes incubation in $2 \mathrm{M} \mathrm{HCl}$ at $37^{\circ} \mathrm{C}$, and 10 minute rinse in $0.1 \mathrm{M}$ boric acid, $\mathrm{pH}$ 8.5. Thereafter, incubation in TBS/0.1\% Triton $\mathrm{X}-100 / 3 \%$ normal donkey serum (TBS-TS) for 30 minutes was followed by incubation with primary antibodies for 48 hours at $4^{\circ} \mathrm{C}$. After washing in TBS-TS, sections were incubated with secondary antibodies for 2 hours, extensively washed in TBS, and mounted on glass slides. Fluorescence was detected using a confocal scanning laser microscope (Leica).

\section{Histological quantification}

A systematic, random counting procedure was used as previously described $(44,67)$. Series of every 10 th section $(400-\mu \mathrm{m}$ interval) were analyzed. For the dentate gyrus, all BrdU-positive cells in the granule cell layer were counted on approximately 6 sections per animal. For colabeling with neuronal marker NeuN to estimate the percentage of neurons among the newly generated cells, 100 randomly selected BrdU-positive cells per animal were analyzed under the confocal microscope. Multiplying the total number of BrdU-positive cells by the percentage of NeuN/BrdU-doublepositive cells yielded the number of new neurons in the dentate gyrus. For the lateral ventricle wall, striatum, and cortex, we systematically analyzed 2 sections per animal by counting cells in 25 adjacent frames $(250 \times 250 \mu \mathrm{m}$ each) arranged in an array of $5 \times 5$ frames starting adjacent to the lesion site. BrdU-positive, DCX-positive, and NeuN/DCX-double positive cells were counted, and the density for each cell type was calculated.

\section{Cultivation of adult neural stem cells}

Neural stem cells were obtained from the hippocampus or SVZ of 4- to 6-week-old male Wistar rats as described in ref. 68. Briefly, animals were sacrificed, and brains were dissected and washed in ice-cold Dulbecco's PBS (DPBS) containing $4.5 \mathrm{~g} / 1$ glucose (DPBS/Glc). The hippocampus and SVZ from 6 animals were dissected, washed in $10 \mathrm{ml} \mathrm{DPBS} / \mathrm{Glc}$, and centrifuged for 5 minutes at $1,600 \mathrm{~g}$ at $4{ }^{\circ} \mathrm{C}$. Tissue was minced using scissors. Tissue pieces were washed again and centrifuged for 5 minutes at $800 \mathrm{~g}$ and the pellet resuspended in $0.01 \%$ (wt/vol) papain, $0.1 \%$ (wt/vol) Dispase II (Roche Diagnostics) (neutral protease), $0.01 \%$ (wt/vol) DNase I, and $12.4 \mathrm{mM}$ manganese sulfate in HBSS. Tissue was incubated for 40 minutes at room temperature.

Subsequently, the suspension was centrifuged at $4{ }^{\circ} \mathrm{C}$ for 5 minutes at $800 \mathrm{~g}$ and the pellet washed 3 times in $10 \mathrm{ml}$ DMEM/Ham's F-12 medium containing $2 \mathrm{mM}$ L-glutamine, $100 \mathrm{U} / \mathrm{ml}$ penicillin/streptomycin. Cells were then resuspended in $1 \mathrm{ml}$ neurobasal medium containing B27 (Invitrogen Corp.), $2 \mathrm{mM}$ L-glutamine, $100 \mathrm{U} / \mathrm{ml}$ penicillin/streptomycin, $20 \mathrm{ng} / \mathrm{ml}$ EGF, $20 \mathrm{ng} / \mathrm{ml} \mathrm{bFGF}$, and $2 \mu \mathrm{g} / \mathrm{ml}$ heparin. Cells were seeded into 6-well plates at a concentration of $25,000-100,000$ cells $/ \mathrm{ml}$ and incubated at $37^{\circ} \mathrm{C}$ in $5 \% \mathrm{CO}_{2}$. Two-thirds of the medium volume was changed weekly (68).

\section{Assessment of differentiation markers in vitro}

Quantitative PCR. Cultured neurospheres (39 DIV) derived from the SVZ were stimulated once with the following G-CSF concentrations: $10 \mathrm{ng} / \mathrm{ml}$,
$100 \mathrm{ng} / \mathrm{ml}$, and $500 \mathrm{ng} / \mathrm{ml}$. Four days after addition of recombinant human G-CSF (NEUPOGEN; Amgen Inc.), cells were harvested for the RNA preparation. Untreated cells served as control. RNA of the G-CSFtreated and untreated neurospheres of the SVZ was isolated using the QIAGEN RNeasy Mini Kit according to the manufacturer's recommendations. cDNA was synthesized from $2 \mu \mathrm{g}$ total RNA using oligo-dT primers, Superscript II Reverse Transcriptase (Invitrogen Corp.). Quantitative PCR was performed using the LightCycler system (Roche Diagnostics Corp.) with SYBR green staining of DNA double strands. Cycling conditions were as follows: nestin and NSE, 3 minutes at $95^{\circ} \mathrm{C}, 5$ seconds at $95^{\circ} \mathrm{C}, 10$ seconds at $58^{\circ} \mathrm{C}, 30$ seconds at $72^{\circ} \mathrm{C}, 10$ seconds at $81^{\circ} \mathrm{C}$ for 50 cycles; $\beta$-III-tubulin, 3 minutes at $95^{\circ} \mathrm{C}, 5$ seconds at $95^{\circ} \mathrm{C}, 10$ seconds at $65^{\circ} \mathrm{C}, 30$ seconds at $72^{\circ} \mathrm{C}, 10$ seconds at $87^{\circ} \mathrm{C}$ for 50 cycles; PLP, 3 minutes at $95^{\circ} \mathrm{C}$, 5 seconds at $95^{\circ} \mathrm{C}, 10$ seconds at $62^{\circ} \mathrm{C}, 30$ seconds at $72^{\circ} \mathrm{C}, 10$ seconds at $84^{\circ} \mathrm{C}$ for 50 cycles; GFAP, 3 minutes at $95^{\circ} \mathrm{C}, 5$ seconds at $95^{\circ} \mathrm{C}, 10$ seconds at $60^{\circ} \mathrm{C}, 30$ seconds at $72^{\circ} \mathrm{C}, 10$ seconds at $81^{\circ} \mathrm{C}$ for 50 cycles. Melting curves were determined using the following parameters: $95^{\circ} \mathrm{C}$ cooling to $50^{\circ} \mathrm{C}$; ramping to $99^{\circ} \mathrm{C}$ at $0.2^{\circ} \mathrm{C} /$ second. The following primer pairs were used: rat nestin-plus, AGGAAGAAGCTGCAGCAGAG; rat nestin-minus, TTCACCTGCTTGGGCTCTAT; rat NSE-plus, GGCAAGGATGCCACTAATGT, rat NSE-minus, AGGGTCAGCAGGAGACTTGA; rat $\beta$-III-tub-716s, CCACCTACGGGGACCTCAACCAC; rat beta III-tub-1022as, GACATGCGCCCACGGAAGACG; rat PLP-518s, TCATTCTTTGGAGCGGGTGTG; rat PLP-927as, TAAGGACGGCAAAGTTGTAAGTGG; rat GFAP3'-1123s, CCTTTCTTATGCATGTACGGAG; rat GFAP3'-1245as, GTACACTAATACGAAGGCACTC. The LightCycler PCR analysis was performed using the SYBR Green master mix, according to the manufacturer's recommendations (Roche Diagnostics Corp.). Specificity of product was ensured by melting point analysis and agarose gel electrophoresis. cDNA content of samples was normalized to the expression level of cyclophilin (primers: cyc5, ACCCCACCGTGTTCTTCGAC; acyc300, CATTTGCCATGGACAAGATG). Relative regulation levels were derived after normalization to cyclophilin and comparison with the untreated cells.

Luciferase assay. To amplify the $\beta$-III-tubulin gene promoter (fragment -450 to +54$)(69)$, rat genomic DNA was used as a template for PCR. The amplified fragment was inserted into the MluI/XhoI site of the pGL3-Basic firefly luciferase reporter vector (Promega) to generate the pGL3-p- $\beta$-IIItubulin experimental vector. For DNA transfection, adult neural stem cells were dissociated and plated on poly-L-ornithin/laminin-coated 96-well plates at a density of 35,000 cells/well. After 24 hours cultivation, cells were washed once with $1 \times$ DPBS (Invitrogen Corp.). Cotransfection with the pGL3-p- $\beta$-III-tubulin vector (150 ng/well) and a Renilla luciferase construct $(100 \mathrm{ng} /$ well) was carried out with the Lipofectamine method (Invitrogen Corp.). The pGL3-Basic firefly luciferase reporter vector served as negative control. The DNA-Lipofectamine 2000 complexes were added to each well after removal of the DPBS, without addition of neurobasal medium. Following the incubation of transfected cells for 24 hours, cells were stimulated with various concentrations of G-CSF in neurobasal medium $(5 \mathrm{ng} / \mathrm{ml}$, $10 \mathrm{ng} / \mathrm{ml}, 100 \mathrm{ng} / \mathrm{ml}$ ) for 48 hours. As a positive control for in vitro differentiation, stem cells were treated by withdrawal of mitogens and addition of 5\% FCS. Using the Dual-Luciferase Reporter Assay System (Promega), we obtained the ratio of luminescence signals from firefly and Renilla luciferase (Mithras LB 940; Berthold Technologies GmbH).

FACS analysis. For differentiation experiments, adult neural stem cells were plated in $15 \mathrm{~cm}^{2}$ culture flasks at a density of 4 million cells and were treated once with $100 \mathrm{ng} / \mathrm{ml} \mathrm{G-CSF}$. A single-cell suspension was made by triturating the neurospheres in 1-ml plastic pipettes and then collected by centrifugation. After resuspension in $1 \times$ PBS, the cells were fixed with $1 \%$ paraformaldehyde. The cells were incubated for 15 minutes on ice, washed once with $1 \times$ PBS, and then permeabilized by resuspension in $0.2 \%$ Tween- 
20. After an incubation on ice for 15 minutes, FCS was added in a 1:50 dilution for blocking. The cells were incubated for 2 hours on ice with a MAP2 antibody (1:50; Sigma-Aldrich) and washed 3 times with $0.1 \%$ Tween20. Following incubation for 30 minutes on ice with a donkey anti-mouse FITC-conjugated secondary antibody (Dianova), the cells were washed again 3 times with $0.1 \%$ Tween- 20 and finally resuspended in $1 \times$ PBS for FACS analysis. Flow cytometry of cells was performed on a FACSCalibur (BD).

\section{Data and statistical analysis}

The values are presented as mean \pm SEM. The 2-tailed Student's $t$ test was used to determine significant difference between infarct volumes. Behavioral measurements were analyzed using the Mann-Whitney rank sum test or the 2-tailed Student's $t$ test where appropriate. Area under the curve was calculated using the trapezoidal algorithm. ANOVA and post-hoc Duncan test were used to determine the statistical significance of differences in physiological parameters and neurogenesis. Statistical analysis was performed with NCSS 2004 software (NCSS). $P<0.05$ was considered statistically significant.

\section{Acknowledgments}

The authors thank Stephan Hennes, Frank Malischewsky, Margit Wolf, Siena Kiess, Claudia Heuthe, Sandra Bettermann, Andrew Irving, Katrin Kauf, Rebecca Würz, Robert Aigner, Gisela Eisenhardt, Nadine Schramm, Frank Herzog, Ulrike Bolz, Maria
Leiße, and Andrea Esser for excellent technical assistance. Special thanks go to Ansgar Brambrink for global ischemia samples and Moritz Rossner, Dieter Newrzella, and Christine Böhm for performing laser microdissection and RNA amplification. This work was supported in part by a grant to H.-G. Kuhn from the VolkswagenStiftung (I/77 887).

Received for publication October 6, 2004, and accepted in revised form May 17, 2005.

Address correspondence to: Armin Schneider, Axaron Bioscience AG, Im Neuenheimer Feld 515, 69120 Heidelberg, Germany. Phone: 49-6221-454713; Fax: 49-6221-454713; E-mail: schneider@axaron.de. Or to: Hans-Georg Kuhn, The Arvid Carlsson Institute for Neuroscience at the Institute for Clinical Neuroscience, Sahlgrenska Academy, Gothenburg University, Medicinaregatan 11, Box 432, 40530 Gothenburg, Sweden. Phone: 46-31-773-3435; Fax: 46-31-773-3401; E-mail: georg.kuhn@neuro. gu.se. Or to: Wolf-Rüdiger Schäbitz, Universitätsklinikum Münster, Klinik und Poliklinik für Neurologie, Albert-Schweitzer-Str. 33, 48149 Münster, Germany. Phone: 49-2518-348171; Fax: 492518-348181; E-mail: schabitz@uni-muenster.de.

\section{Krüger and T. Steigleder contributed equally to this work.}

1. Fisher, M., and Schaebitz, W. 2000. An overview of acute stroke therapy: past, present, and future [review]. Arch. Intern. Med. 160:3196-3206.

2. Jin, K., et al. 2001. Neurogenesis in dentate subgranular zone and rostral subventricular zone after focal cerebral ischemia in the rat. Proc. Natl. Acad. Sci. U. S. A. 98:4710-4715.

3. Liu, J., Solway, K., Messing, R.O., and Sharp, F.R. 1998. Increased neurogenesis in the dentate gyrus after transient global ischemia in gerbils. J. Neurosci. 18:7768-7778.

4. Burgess, A.W., and Metcalf, D. 1980. Characterization of a serum factor stimulating the differentiation of myelomonocytic leukemic cells. Int. J. Cancer. 26:647-654.

5. Frampton, J.E., Lee, C.R., and Faulds, D. 1994. Filgrastim. A review of its pharmacological properties and therapeutic efficacy in neutropenia [review]. Drugs. 48:731-760.

6. Welte, K., et al. 1985. Purification and biochemical characterization of human pluripotent hematopoietic colony-stimulating factor. Proc. Natl. Acad. Sci. U. S. A. 82:1526-1530.

7. Begley, C.G., et al. 1986. Purified colony-stimulating factors enhance the survival of human neutrophils and eosinophils in vitro: a rapid and sensitive microassay for colony-stimulating factors. Blood. 68:162-166.

8. Hu, B., and Yasui, K. 1997. Effects of colony-stimulating factors (CSFs) on neutrophil apoptosis: possible roles at inflammation site. Int. J. Hematol. 66:179-188.

9. Schabitz, W.R., et al. 2003. Neuroprotective effect of granulocyte colony-stimulating factor after focal cerebral ischemia. Stroke. 34:745-751.

10. Aronowski, J., Strong, R., and Grotta, J.C. 1997. Reperfusion injury: demonstration of brain damage produced by reperfusion after transient focal ischemia in rats. J. Cereb. Blood Flow Metab. 17:1048-1056.

11. Aloisi, F., et al. 1992. Production of hemolymphopoietic cytokines (IL-6, IL-8, colony-stimulating factors) by normal human astrocytes in response to IL-1 beta and tumor necrosis factor-alpha. J. Immunol. 149:2358-2366.

12. Kuroki, M., and O'Flaherty, J.T. 1999. Extracellular signal-regulated protein kinase (ERK)-dependent and ERK-independent pathways target STAT3 on serine-727 in human neutrophils stimulated by chemotactic factors and cytokines. Biochem. J. 341:691-696.

13. Graham, S.H., Chen, J., and Clark, R.S. 2000. Bcl-2 family gene products in cerebral ischemia and traumatic brain injury. J. Neurotrauma. 17:831-841.

14. Seo, S.R., et al. 2001. Zn2+-induced ERK activation mediated by reactive oxygen species causes cell death in differentiated PC12 cells. J. Neurochem. 78:600-610.

15. Anderson, C.N., and Tolkovsky, A.M. 1999. A role for MAPK/ERK in sympathetic neuron survival: protection against a 553 -dependent, JNK-independent induction of apoptosis by cytosine arabinoside. J. Neurosci. 19:664-673.

16. Watson, F.L., et al. 2001. Neurotrophins use the Erk5 pathway to mediate a retrograde survival response. Nat. Neurosci. 4:981-988.

17. Dudek, H., et al. 1997. Regulation of neuronal survival by the serine-threonine protein kinase Akt. Science. 275:661-665.

18. Matthews, J.N., Altman, D.G., Campbell, M.J., and Royston, P. 1990. Analysis of serial measurements in medical research. BMJ. 300:230-235.

19. Brown, J.P., et al. 2003. Transient expression of doublecortin during adult neurogenesis. J. Comp. Neurol. 467:1-10.

20. Gleeson, J.G., Lin, P.T., Flanagan, L.A., and Walsh, C.A. 1999. Doublecortin is a microtubule-associated protein and is expressed widely by migrating neurons. Neuron. 23:257-271.

21. Mullen, R.J., Buck, C.R., and Smith, A.M. 1992. NeuN, a neuronal specific nuclear protein in vertebrates. Development. 116:201-211.

22. Goings, G.E., Sahni, V., and Szele, F.G. 2004. Migration patterns of subventricular zone cells in adult mice change after cerebral cortex injury. Brain Res. 996:213-226.

23. Jin, K., et al. 2003. Directed migration of neuronal precursors into the ischemic cerebral cortex and striatum. Mol. Cell. Neurosci. 24:171-189.

24. Arvidsson, A., Kokaia, Z., and Lindvall, O. 2001. $\mathrm{N}$-methyl-D-aspartate receptor-mediated increase of neurogenesis in adult rat dentate gyrus following stroke. Eur. J. Neurosci. 14:10-18.
25. Gu, W., Brannstrom, T., and Wester, P. 2000. Cortical neurogenesis in adult rats after reversible photothrombotic stroke. J. Cereb. Blood Flow Metab. 20:1166-1173.

26. Jiang, W., Gu, W., Brannstrom, T., Rosqvist, R., and Wester, P. 2001. Cortical neurogenesis in adult rats after transient middle cerebral artery occlusion. Stroke. 32:1201-1207.

27. Kee, N.J., Preston, E., and Wojtowicz, J.M. 2001. Enhanced neurogenesis after transient global ischemia in the dentate gyrus of the rat. Exp. Brain Res. 136:313-320.

28. Nagata, S., et al. 1986. Molecular cloning and expression of cDNA for human granulocyte colony-stimulating factor. Nature. 319:415-418.

29. Wesselingh, S.L., Gough, N.M., Finlay-Jones, J.J., and McDonald, P.J. 1990. Detection of cytokine mRNA in astrocyte cultures using the polymerase chain reaction. Lymphokine Res. 9:177-185.

30. Schneider, A., et al. 2004. Restriction-mediated differential display (RMDD) identifies pip92 as a pro-apoptotic gene product induced during focal cerebral ischemia. J. Cereb. Blood Flow Metab. 24:224-236.

31. Kokaia, Z., et al. 1993. Coexpression of neurotrophins and their receptors in neurons of the central nervous system. Proc. Natl. Acad. Sci. U. S. A. 90:6711-6715.

32. Shingo, T., Sorokan, S.T., Shimazaki, T., and Weiss, S. 2001. Erythropoietin regulates the in vitro and in vivo production of neuronal progenitors by mammalian forebrain neural stem cells. J. Neurosci. 21:9733-9743.

33. Ogunshola, O.O., et al. 2002. Paracrine and autocrine functions of neuronal vascular endothelial growth factor (VEGF) in the central nervous system. J. Biol. Chem. 277:11410-11415.

34. Barnabe-Heider, F., and Miller, F.D. 2003. Endogenously produced neurotrophins regulate survival and differentiation of cortical progenitors via distinct signaling pathways. J. Neurosci. 23:5149-5160.

35. Brines, M.L., et al. 2000. Erythropoietin crosses the blood-brain barrier to protect against experimental brain injury. Proc. Natl. Acad. Sci. U. S. A. 97:10526-10531.

36. McLay, R.N., Kimura, M., Banks, W.A., and Kastin, 
A.J. 1997. Granulocyte-macrophage colony-stimulating factor crosses the blood--brain and blood-spinal cord barriers. Brain. 120:2083-2091.

37. Dong, F., Gutkind, J.S., and Larner, A.C. 2001. Granulocyte colony-stimulating factor induces ERK5 activation, which is differentially regulated by protein-tyrosine kinases and protein kinase $\mathrm{C}$. Regulation of cell proliferation and survival. J. Biol. Chem. 276:10811-10816.

38. Brunet, A., Datta, S.R., and Greenberg, M.E. 2001. Transcription-dependent and -independent control of neuronal survival by the PI3K-Akt signaling pathway. Curr. Opin. Neurobiol. 11:297-305.

39. Chakraborty, A., et al. 1996. Granulocyte colonystimulating factor activation of Stat 3 alpha and Stat 3 beta in immature normal and leukemic human myeloid cells. Blood. 88:2442-2449.

40. Dong, F., and Larner, A.C. 2000. Activation of Akt kinase by granulocyte colony-stimulating factor (G-CSF): evidence for the role of a tyrosine kinase activity distinct from the Janus kinases. Blood. 95:1656-1662.

41. Magavi, S.S., Leavitt, B.R., and Macklis, J.D. 2000 Induction of neurogenesis in the neocortex of adult mice. Nature. 405:951-955.

42. Arvidsson, A., Collin, T., Kirik, D., Kokaia, Z., and Lindvall, O. 2002. Neuronal replacement from endogenous precursors in the adult brain after stroke. Nat. Med. 8:963-970.

43. Williams, G.T., Smith, C.A., Spooncer, E., Dexter, T.M., and Taylor, D.R. 1990. Haemopoietic colony stimulating factors promote cell survival by suppressing apoptosis. Nature. 343:76-79.

44. Winner, B., Cooper-Kuhn, C.M., Aigner, R., Winkler, J., and Kuhn, H.G. 2002. Long-term survival and cell death of newly generated neurons in the adult rat olfactory bulb. Eur. J. Neurosci. 16:1681-1689.

45. Biebl, M., Cooper, C.M., Winkler, J., and Kuhn, H.G. 2000. Analysis of neurogenesis and programmed cell death reveals a self-renewing capacity in the adult rat brain. Neurosci. Lett. 291:17-20.

46. Dayer, A.G., Ford, A.A., Cleaver, K.M., Yassaee, M., and Cameron, H.A. 2003. Short-term and longterm survival of new neurons in the rat dentate gyrus. J. Comp. Neurol. 460:563-572.

47. Sun, W., et al. 2004. Programmed cell death of adultgenerated hippocampal neurons is mediated by the proapototic gene Bax. J. Neurosci. 24:11205-11213.
48. Fabel, K., et al. 2003. VEGF is necessary for exercise-induced adult hippocampal neurogenesis. Eur. J. Neurosci. 18:2803-2812.

49. Schanzer, A., et al 2004. Direct stimulation of adult neural stem cells in vitro and neurogenesis in vivo by vascular endothelial growth factor. Brain Pathol. 14:237-248.

50. Pencea, V., Bingaman, K.D., Wiegand, S.J., and Luskin, M.B. 2001. Infusion of brain-derived neurotrophic factor into the lateral ventricle of the adult rat leads to new neurons in the parenchyma of the striatum, septum, thalamus, and hypothalamus. J. Neurosci. 21:6706-6717.

51. Zigova, T., Pencea, V., Wiegand, S.J., and Luskin, M.B. 1998. Intraventricular administration of BDNF increases the number of newly generated neurons in the adult olfactory bulb. Mol. Cell. Newrosci. 11:234-245.

52. Bland, B.H., and Oddie, S.D. 2001. Theta band oscillation and synchrony in the hippocampal formation and associated structures: the case for its role in sensorimotor integration [review]. Behav. Brain Res. 127:119-136.

53. Dypvik, A.T., and Bland, B.H. 2004. Functional connectivity between the red nucleus and the hippocampus supports the role of hippocampal formation in sensorimotor integration. J. Neurophysiol. 92:2040-2050

54. van Lier, H., Coenen, A.M., and Drinkenburg, W.H. 2003. Behavioral transitions modulate hippocampal electroencephalogram correlates of open field behavior in the rat: support for a sensorimotor function of hippocampal rhythmical synchronous activity. J. Neurosci. 23:2459-2465.

55. Muir, G.M., and Bilkey, D.K. 2003. Theta- and movement velocity-related firing of hippocampal neurons is disrupted by lesions centered on the perirhinal cortex. Hippocampus. 13:93-108.

56. Rhodes, J.S., et al. 2003. Exercise increases hippocampal neurogenesis to high levels but does not improve spatial learning in mice bred for increased voluntary wheel running. Behav. Neurosci. 117:1006-1016.

57. van Praag, H., Kempermann, G., and Gage, F.H 1999. Running increases cell proliferation and neurogenesis in the adult mouse dentate gyrus. Nat. Neurosci. 2:266-270.

58. Brown, J., et al. 2003. Enriched environment and phys- ical activity stimulate hippocampal but not olfactory bulb neurogenesis. Eur. J. Neurosci. 17:2042-2046.

59. Six, I., Gasan, G., Mura, E., and Bordet, R. 2003. Beneficial effect of pharmacological mobilization of bone marrow in experimental cerebral ischemia. Eur. J. Pharmacol. 458:327-328.

60. Shyu, W.C., et al. 2004. Functional recovery of stroke rats induced by granulocyte colony-stimulating factor-stimulated stem cells. Circulation. 110:1847-1854.

61. Watson, B.D., Dietrich, W.D., Busto, R., Wachtel, M.S., and Ginsberg, M.D. 1985. Induction of reproducible brain infarction by photochemically initiated thrombosis. Ann. Neurol. 17:497-504.

62. Schallert, T., Fleming, S.M., Leasure, J.L., Tillerson, J.L., and Bland, S.T. 2000. CNS plasticity and assessment of forelimb sensorimotor outcome in unilateral rat models of stroke, cortical ablation, parkinsonism and spinal cord injury. Neuropharmacology. 39:777-787.

63. Schabitz, W.R., et al. 2004. Effect of brain-derived neurotrophic factor treatment and forced arm use on functional motor recovery after small cortical ischemia. Stroke. 35:992-997.

64. Schallert, T., Kozlowski, D.A., Humm, J.L., and Cocke, R.R. 1997. Use-dependent structural events in recovery of function. Adv. Neurol. 73:229-238.

65. Germano, A.F., Dixon, C.E., d'Avella, D., Hayes, R.L., and Tomasello, F. 1994. Behavioral deficits following experimental subarachnoid hemorrhage in the rat. J. Neurotrauma. 11:345-353.

66. Eisenhut, M., and Mier, W. 2003. Radioiodination chemistry and radioiodinated compounds. In Handbook of nuclear chemistry. Volume 4. A. Vértes, S. Nagy, and Z. Klencsár, editors. Kluwer Academic Publishers. Amsterdam, The Netherlands. 257-278.

67. Cooper-Kuhn, C.M., et al. 2002. Impaired adult neurogenesis in mice lacking the transcription factor E2F1. Mol. Cell. Neurosci. 21:312-323.

68. Ray, J., Peterson, D.A., Schinstine, M., and Gage, F.H. 1993. Proliferation, differentiation, and longterm culture of primary hippocampal neurons. Proc. Natl. Acad. Sci. U. S. A. 90:3602-3606.

69. Dennis, K., Uittenbogaard, M., Chiaramello, A., and Moody, S.A. 2002. Cloning and characterization of the 5 '-flanking region of the rat neuron-specific Class III beta-tubulin gene. Gene. 294:269-277. 